\title{
IS FINANCIAL ANALYSIS USELESS?
}

\author{
The Proceedings of a Seminar on the \\ Efficient Capital Market and \\ Random Walk Hypotheses
}

\author{
William F. Sharpe \\ Frank E. Block \\ Edmund A. Mennis \\ Jack L. Treynor \\ Michael C. Jensen \\ Jerome L. Valentine \\ Neil Wright
}

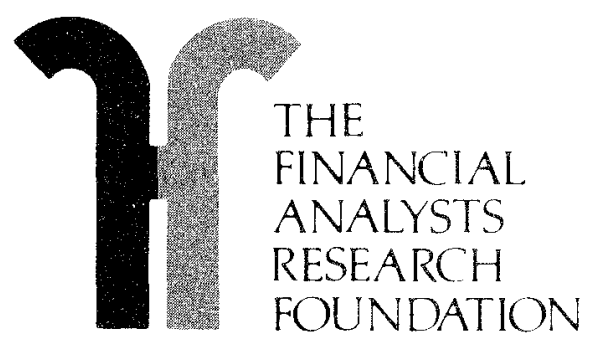




\author{
Lopright 1975

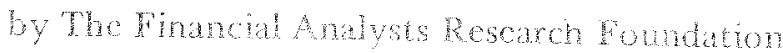 \\ Charloteswle, Virghid
}

10-digit I SBN: 1-934667-13-7 13-digit I SBN: 978-1-934667-13-2 


\section{ONTENTS}

PREFACE

ABOUT THE AUTHORS

Efficient Capital Markets: A Review of the TheoryWilliam F. Sharpe . . . . . . . . . . . . . 1

Efficient Capital Markets-A Practitioner's View-

Edmund A. Mennis

Tests of Captial Market Theory and Implications of the

Evidence-Michael C. Jensen . . . . . . . . . . . . . . 29

Capital Market Theory and Implications of the

Evidence-Frank E. Block . . . . . . . . . . . 49

Long Term Investing-Jack L. Treynor . . . . . . . 53

The Capital Asset Pricing Model From A Professional's

Point of View-Jerome L. Valentine . . . . . . . . 61

Discussion of Capital Market Theory-Neil Wright . . . . 81 


\section{THE FINANCIAL ANALYSTS RESEARCH FOUNDATION AND ITS PUBLICATIONS}

1. The Financial Analysts Research Foundation is an autonomous charitable foundation, as defined by Section 501(c)(3) of the Internal Revenue Code. The Foundation seeks to improve the professional performance of financial analysts by fostering education, by stimulating the development of financial analysis through high quality research, and by facilitating the dissemination of such research to users and to the public. More specifically, the purposes and obligations of the Foundation are to commission basic studies (1) with respect to investment securities analysis, investment management, financial analysis, securities markets and closely related areas that are not presently or adequately covered by the available literature, (2) that are directed toward the practical needs of the financial analyst and the portfolio manager, and (3) that are of some enduring value. Within the constraints of the above obligations, the Foundation cooperates with other organizations, such as The Financial Analysts Federation and The Institute of Chartered Financial Analysts, that to a substantial degree share mutual interests and objectives.

2. Several types of studies and publications are authorized:

A. Studies based on existing knowledge or methodology which result in a different arrangement of the subject. Included in this category are papers that seek to broaden the understanding within the profession of financial analysis through reviewing, distilling, or synthesizing previously published theoretical research, empirical findings, and specialized literature;

B. Studies that apply known techniques, methodology, and quantitative methods to problems of financial analysis;

C. Studies that develop new approaches or new solutions to important problems existing in financial analysis;

D. Pioneering and original research that discloses new theories, new relationships, or new knowledge that confirms, rejects, or extends existing theories and concepts in financial analysis. Ordinarily, such research is intended to improve the state of the art. The research findings may be supported by the collection or manipulation of empirical or descriptive data from primary sources, such as original records, field interviews, or surveys.

3. The views expressed in the publications are those of the authors and do not necessarily represent the official position of the Foundation, its Board of Trustees, or its staff. As a matter of policy, the Foundation has no official position with respect to specific practices in financial analysis.

4. The Foundation is indebted to the voluntary financial support of its institutional and individual sponsors by which this and other publications are made possible. As a 501 (c)(3) foundation, contributions are welcomed from interested donors, including individuals, business organizations, institutions, estates, foundations, and others. Inquiries may be directed to:

\section{Executive Director}

The Financial Analysts Research Foundation

University of Virginia, Post Office Box 3668

Charlottesville, Virginia 22903

(804) $977-6600$ 


\section{THE FINANCIAL ANALYSTS RESEARCH FOUNDATION}

1974-1975

\section{Board of Trustees and Officers}

David G. Watterson, C.F.A., President

Boyd, Watterson \& Co., Cleveland

Jerome L. Vaientine, C.F.A., Vice President

Texas Commerce Bank N. A., Houston

Leonard E. Barlow, C.F.A., Secretary-Treasurer

McLeod, Young, Weir \& Company Limited

Toronto

W. Scott Bauman, C.F.A., Executive Director University of Virginia, Charlottesville

Gordon R. Ball, C.F.A.

Martens, Ball, Albrecht Securities Limited

Toronto

Frank E. Block, C.F.A.

Shields Model Roland Incorporated

New York

Roger F. Murray

Columbia University, New York
Jack L. Treynor

Financial Analysts Journal

New York

\section{Ex-Officio}

William S. Gray, III, C.F.A.

Harris Trust and Savings Bank, Chicago

Chairman, The Financial Analysts Federation

Robert E. Blixt, C.F.A.

Minnesota State Board of Investment, St. Paul

President. The Institute of Chartered

Financial Analysts

C. Stewart Sheppard

University of Virginia

Dean, The Colgate Darden Graduate School of Business Administration

\section{Finance Committee}

Gordon R. Ball, C.F.A., Chairman

Martens, Ball, Albrecht Securities Limited

Toronto

Leonard E. Barlow, C.F.A.

McLeod, Young, Weir \& Company Limited Toronto

George S. Bissell, C.F.A.

Massachusetts Financial Services, Inc.

Boston

Calvin S. Cudney, C.F.A.

The Cleveland Trust Company

Cleveland

William R. Grant, C.F.A.

Smith Barney \& Co. Incorporated

New York

William S. Gray, III, C.F.A.

Harris Trust and Savings Bank

Chicago

Robert E. Gunn, C.F.A.

Financial Counselors, Inc., Kansas City

Frank X. Keaney, C.F.A.

G. H. Walker, Laird Incorporated

St. Louis

George Stevenson Kemp, Jr., C.F.A.

Paine, Webber, Jackson \& Curtis Inc.

Richmond

\section{Staff}

W. Scott Bauman, C.F.A., Executive Director University of Virginia

Charlottesville
Richard W. Lambourne, C.F.A.

Grocker Investment Management Corporation San Francisco

James G. McCormick, C.F.A.

Eppler, Guerin \& Turner, Inc.

Dallas

David G. Pearson, C.F.A.

Blyth Eastman Dillon \& Co. Incorporated

Los Angeles

LeRoy F. Piche, C.F.A.

Northwest Bancorporation, Minneapolis

Morton Smith, C.F.A.

Philadelphia

Raymond L. Steele, C.F.A.

The Robinson-Humphrey Company, Inc.

Atlanta

David G. Watterson, C.F.A.

Boyd, Watterson \& Co., Cleveland

David D. Williams, C.F.A.

National Bank of Detroit

Detroit

Gotuon T. Wise, C.F.A.

First Gily National Bank

Iruston

Robert H. Trent, Project Administrator

University of Virginia

Chariottesville 



\section{PHA}

This procedings issue consists of the papers presented at the first

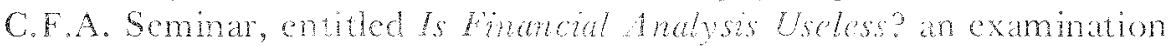
of the cfickent maket hypothesis and the matom walk hypothesis. The semina was hed in Iouston on Nay 20 1974, and sponsored jointy by The Instive of Chanered Finacial Analysts and The

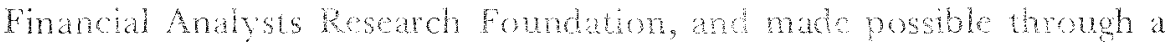
grant fron Texis Commerce bank.

A central thene of this procedimgs is the critical apprasal of the

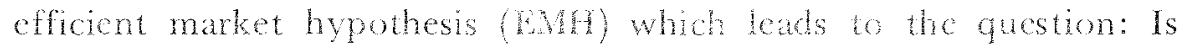
financial analysis (or professional mvestmon management) useless?

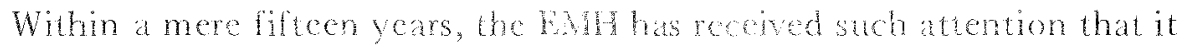
has become the most hotly debated thoory today among financial analysts and is considered by some to be sterious challenge to the very foundation of traditional investmen practices currenty followed by many professional andysts.

1 belicve it will be bonefictal for us to examine critically this subject in thec distinet steps:

1. We should carefuly shdy the asmmptions, lomic, limitations, and conclusions of capital market heory and the EMI as they pertain to portfolio managenent and securty analysis.

2. We shoud review the ampical evience and research Inding used both to support and to refute these theories.

3. Finally, we should develop an understanding of the contributions and limitions of these studies.

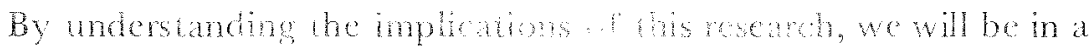

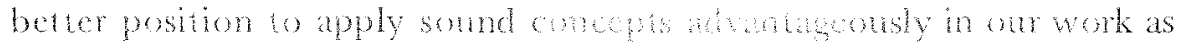

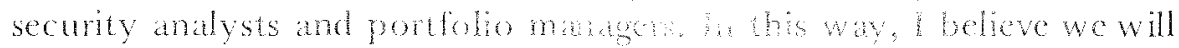

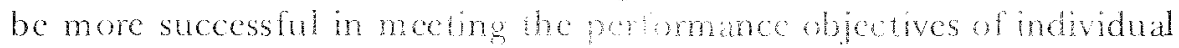
and institutional investors, and in mprophete comboling their exposure to risk. For mestors seche supuror invesment retums, empirical resureh sugsesis that in estmen mangomont expenses and portholio tumowe shoud be carchly wonelled, that diversification should be somentat restrieted, and that mique or distincive 
approaches should be considered in developing portfolio strategies and in selecting securities which appear undervalued. Undervalued securities, in the jargon of modem portfolio theory, are securities which offer abnomal or excess retums. This is what the EMH game is all about.

These papers provide us with extremely valuable insights into these vitally important issues. We are indeed fortunate to have such an outstanding collection of papers presented by internationally recognized scholars and professional financial analysts.

We wish to express a warm gratitude to our speakers and several others whose efforts made this new seminar series such a success. Special recognition is extended to Mr. Robert D. Milne, C.F.A., Dr. Fdmund A. Mennis, C.F.A., and Mr. Frank E. Block, C.F.A., who served on the general plamning committee, Mr. Donald W. Jones, C.F.A., Dr. Jerome L. Valentine, C.X.A., Professor James A. Largay, III, and Dr. Gaston Rimliner, who superbly planned the program and seminar arrangements in Houston. Very decp appreciation is expressed for the generous grant made by Texas Commere Bank in launching this first C.F. A. Seminar. Special thanks go to Rice University for its sponsorhip of the program and for the use of its fine facilities.

I wish to thank the staff for its dedicated assistance in the administration of this project, Mrs. Beatrice Gordon for handling the seminar registration, Dr. Robert 11 . Trent for editorial supervision of the proceedings issue, Mrs Mary D. Shelton for publication production, and Mrs. Miranda Collins for copy preparation.

W. Scott Bauman, C.F.A. Executive Director 


\section{ABOUT THE AUTHORS}

Mr. Frank E. Block, C.H.A.

Mr. Block is a partner and Director of Research at Shields Model Roland Incorporated. He is an Associate Editor of the Financial Analysts Journal and a member of the editorial boand of The C.F.A. Digest, and a member of the Board of Trustees of The Financial Analysts Research Foundation. Mr. Block is a past President of both The Institute of Chartered Financial Analysts and The Financial Analysts Federation.

Dr. Michael C. Jensen

Dr. Jensen is Associate Professor in the Graduate School of Management, University of Rochester. He has published numerous articles and books, and received several grants and fellowships, including ones from the Ford Foundation, National Science Foundation, and the American Bankers Association. He received his Ph.D. and M.B.A. from the University of Chicago.

Dr. Edmund A. Mennis, C.F.A.

Dr. Mennis is Senior Vice President and Chairman of the Investment Policy Committee of Security Pacilic National Bank. He was a member of the Board of Trustees of The Institute of Chartered Financial Analysts for six years and served two terms as President. Dr. Mennis is a frequent contributor to professional publications. In 1972 he received the Nicholas Molodovsky Award from The Financial Analysts Federation. Dr. Mennis is Editor of The C.F.A. Digest and an Associate Editor of the Financial Analysts Journal. He received his B.A. from the City University of New York, his M.A. from Columbia University, and his Ph.D. from New York University.

Dr. William F. Sharpe

Dr. Sharpe is Timken Professor of Finance in the Graduate School of Business, Stanford University. He has written four books, including Portfolio Theory and Capital Markets (McGraw-Hill, 1970), and his 
works appear in the Joumal of Finance, the Financial Analysts Journal, The Joumal of Financial and Quantitative Analyses, and other professional publications. He serves as Advisor to the Computer Applications Deparment of Merrill Lynch, Pierce, Fenner \& Smith, Inc. He is perhaps best known in the investment community for his development of the Shampe Dagonal Model and for his imovative use of the Greek alphabet, especially Beta. Dr. Sharpe received his Ph.D. in Economics from U.C.L.A.

Mr. Jack L. Trevour

As Editor of the Financial Analysts Joumal, Mr. Treynor has provided valuable leadership in exposing financial analysts to significant issues and thoughts which are both challenging and stimulating. He is the author of many joumal articks, a few of which are already considered to be classics. Mr. Treynor is a member of the Board of Trustees of The Financial Analysts Research Foundation.

Dr. Jerome L. Valentine, C.F.A.

Dr. Valentine is Vice President and Trust Officer of Texas Commerce Bank. He is an author of several innovative publications, including a book entitled Quantitative Techniques for Financial Analysis and an Occasional Paper entitled Investment Analysis and Capital Market Theory. Dr. Valentine is a member of the Editorial Board of The C.F.A. Digesl, and a member of the Board of Trustees of The Financial Analysts Research Foundation.

Dr. Neil Wright

Dr. Wright is a Professor in the Department of Economics and Accounting, Rice University. He is a recognized scholar in the field of finance. 


\section{EFFICIENT CAPITAL MARKETS: A REVIEW OF THE THEORY}

\section{William F. Sharpe}

Recent years have seen the rapid development and considerable acceptance of the subject variously called efficient capital market theory, beta theory, portfolio theory, random walk theory, etc. Along with this has come substantial hostility and widespread confusion. This paper is designed to provide a basis for a continuing discussion of the merits and drawbacks of this line of inquiry. Modifications of the theory, criticisms, and empirical tests will be discussed little if at all. Instead, we will concentrate on the theory in its original form.

Two ground rules need to be established. First, in the tradition of modern economic theory, the issue of the relevance of the assumptions will not be considered directly. The very nature of theorizing requires the adoption of unrealistic assumptions, for the real world is too complex for careful analysis. Instead, one must abstract those few aspects that appear to be most important. The test of success in this endeavor is the consistency between the implications of the theory and the relevant attributes of the real world. The most important questions, then, are whether the conclusions reached are reasonably consistent with reality, and how the theory compares with alternative approaches that are capable of guiding decisions.

Second, it is important to emphasize that in this discussion, only subjective estimates of the future, of the type that could be made by security analysts will be considered. No assumption is made that historic data processed by computers are necessarily relevant, without modification by human beings. Efficient market theory is almost completely dependent on the assumption that clever, well-informed analysts constantly review available information and process it in relevant ways. This certainly requires computer analysis of past data, but undoubtedly much more is needed.

\footnotetext{
"One modification (the "zero-beta" version) is described in the paper by Michael Jensen included in this volume.
} 


\section{Maket Lfliciency}

The key idea behind the theory is that of maket efficiency. This was born as "random walk"-a tem that has unpleasant comotations and is not even appropriate in a technical sense. The term "market efficiency" is both more satistying and more correct. Definition is difficult, but the idea is that a market is efficient if there are many very bright, very well-informed andysts constanty searching for securities that are mispriced. As long as this force is operative, when information becomes reasonably public, it will lead to transactions that will shortly cause prices to reflect the information appropriately. As a result, the price of a secunty will rarely diverge significantly for long from its intrinsic value, where the latter is defined as the certain present value of the uncertain future prospects assessed by a clever, well-informed analyst.

There are, of course, shades and gradations of efficiency. A hardline view would hold that the market is so efficient that prices virtually always reflect amost all avalable information. A more moderate view would hold that widely avalable information is reflected in prices quite rapidly. In cither case, the relationship between price and value refers to the latter as assessed at the time. In retrospect, with hindsight, it is possible to show that most securities have been "mispriced" in some sense. But this involves information not available at the time. Maket efficiency only requires that currently available information be properly reflected in price.

In the real world, of course, there are differences of opinion and differences in circumstances (tax situations, legal constraints, etc.). For purposes of deriving a simple theory, most of these will be ignored. However, it is worthwhile to consider briefly the possible interpretation of market efficiency in these circumstances.

As Jack Treynor has pointed out in a recent issue of the Financial Analysts foumal, most investors can reasonably take the price of a security at any time as a given. In the absence of restrictions, each investor should adjust his or her holdings until the marginal value of aich security equals its price. Aler this adjustment, everyone would agree that every security was "comectly" priced, in the sense that one more or one less share would be "worth" the same amount to each investor.

There are some needed qualifications to this statement. Most importantly, institutional constraints and requirements for short sales 
lead to a range of prices over which a given investor should take neither a long nor a short position. Even without considering this, however, the problem of defining "mispriced" securities remains.

An investor might be said to consider a securty "overpriced" if he or she chooses to invest less than a marketvalue proportion in the security, and might be said to consider a security "underpriced" if more than a market-value proportion is invested. However, some differences in holdings are atwibutable to diferences in circumstances (tax considerations, legal constraints, etc.). A potentially more uscful definition might equate a feeling that a security is under or orerpriced with a decision to invest more or less (respectively) in it than would have been invested had the analyst known only the most rudimentary facts about it (e.g., its yield, sensitivity to market swings, ctc.).

Fortunately, resolution of this issue is not essential for the material to follow. Let us leave it then, to the scmanticists.

\section{Historical Development}

Important aspects of efficient maket theory can be traced back to Bachelier, Irving Fisher, Graham and Dodd, and J. B. Williams. However, none of these authors constructed a rigorous theory explicitly taking uncertainty into account. This task has been accomplished only in the last 25 years.

Two major approaches to the subject are currenty in use. The more general theory is the time-state-preference molel developed by Arrow and Debreu. This is being employed increasingly in the field of finance, greatly increasing our understanding of optimal corporate capital structure, the efficiency of financial markets, etc. However, most work in investments has thus far reled on the Capial Asset Pricing Model (CAPM) and portfolio thon, from which it was derived. We will follow that tradition here.

Three philosophically distinct phases stand out in the development of efficient maket theory. The finst we the essential contribution of Markowite in 1952. Markowite dealt wh the nomative problem of constructing an approprate pertiolio, given analysts csimates of possible future retums from securiks. He suguested that boh risk and retum be considered, provided a fomal methed for measuring both, and showed how relatonships among secunty retums could be taken into aresunt in the andysis. Markeste dectlong tangentially with the 
question of appropriate estimates and the manner in which security prices might be determined in the marketplace.

$A$ series of subsequent contributions increased the practicality of Markowitz's procedures. Tobin, dealing with a somewhat different issue, showed that the ability to borrow or lend funds at a riskless rate of interest makes it possible to separate the portfolio decision in to the determination of a preferred combination of risky securities and then the determination of an appropriate degree of leverage. Others suggested simplified models of the relationships among securities and computer algorithms to exploit them. But all this work remained nomative, directed towards actual decision-making by portfolio managers, and avoided the issue of price determination in the marketplace.

The second major phase began in 1964 with papers by Sharpe, Lintner, and Mossin. The focus was positive, rather than normative-that is, devoted to the question of "what is" rather than that of "what should be." Investors were assumed to be equally well-informed and to be following Markowitz's recommendations. Given such a world, what could be said about security prices? What would be the relationship between risk and return? What types of risk would be rewarded and what types would not? The Capital Asset Pricing Model was intended to provide answers to such questions.

The third phase is in process today. Given a market almost or entirely consistent with the implications of the Capital Asset Pricing Model, what sorts of policies should an investment organization adopt? In short, what sort of normative rules make sense in the context of a market consistent with a positive model of market efficiency? A key contribution along these lines is the recent paper by Treynor and Black. In a broader sense, almost all informed discussion of investment policy can be considered part of this phase.

The remainder of this paper is designed to cover the essential ingredients of the Capital Asset Pricing Model. The approach will be far from rigorous, and a number of comers will be cut in the interests of clarity and simplicity. But hopefully it will provide the desired base for further discussions.

\section{The Capital Asset Pricing Model}

To begin, we need to concentrate on some holding period. For concreteness, assume 90 days. We are going to focus on analysts' 
expectations conceming rate of return over the holding period-i.e., yield plus price change. To keep matters simple, we will disregard tax considerations, institutional restrictions on spending out of capial gains, etc.

Two types of irvestment play an important role in the analysis. The first is a riskless investment, which gives some rate of retum with certainty. For a 90day holding perod, a treasury bill would be appropriate of course, this is riskless only in dollar terms, but again, to keep things simple, we will avoid the problems having to do with real versus doliar values.

When analyzing a risky investment, it is important to remember that there is a riskless alternative. Thus the actual retum on a risky investment should be compared to that which could have been obtained on a riskless investment. To cmphasize this comparison, it is useful to deal in excess retum the return over and above (if positive) or below (if negative) the interest rate on, say, treasury bills. Our analysis will use this measure.

The second key investment is termed "the market portfolio." Formally, it represents a portfolio of all available investments, each held in proportion to its total dollar value outstanding (at market). As a practical matter, we often use a measure such as Standard and Poor's 500-stock index as a surrogate. However, we will deal with the more all-inclusive concept here.

The market portfolio is especially important because it represents the ultimate in attainable diversification. It follows that the risk associated with the market portfolio is all unavoidable-it cannot be diversified away. And this suggests the kind of risk that is unavoidable when considering a single stock: the risk that is attributable to market swings.

These considerations suggest that it is useful to think about the prospects for a stock in terms of a characteristic line. Figure 1 shows an example. This is not intended to be a picture of something that has happened. Rather, it is a picture of an malyst's fedings about what might happen in the future. His or her feeings may be summarized in three measures:

1. Alpha-the intercept of the the: the cxcess retum on the security that the analyst would expect if the maket excess retum were zero (i.e., the reum on the market portfolio equaled the interest rate). 


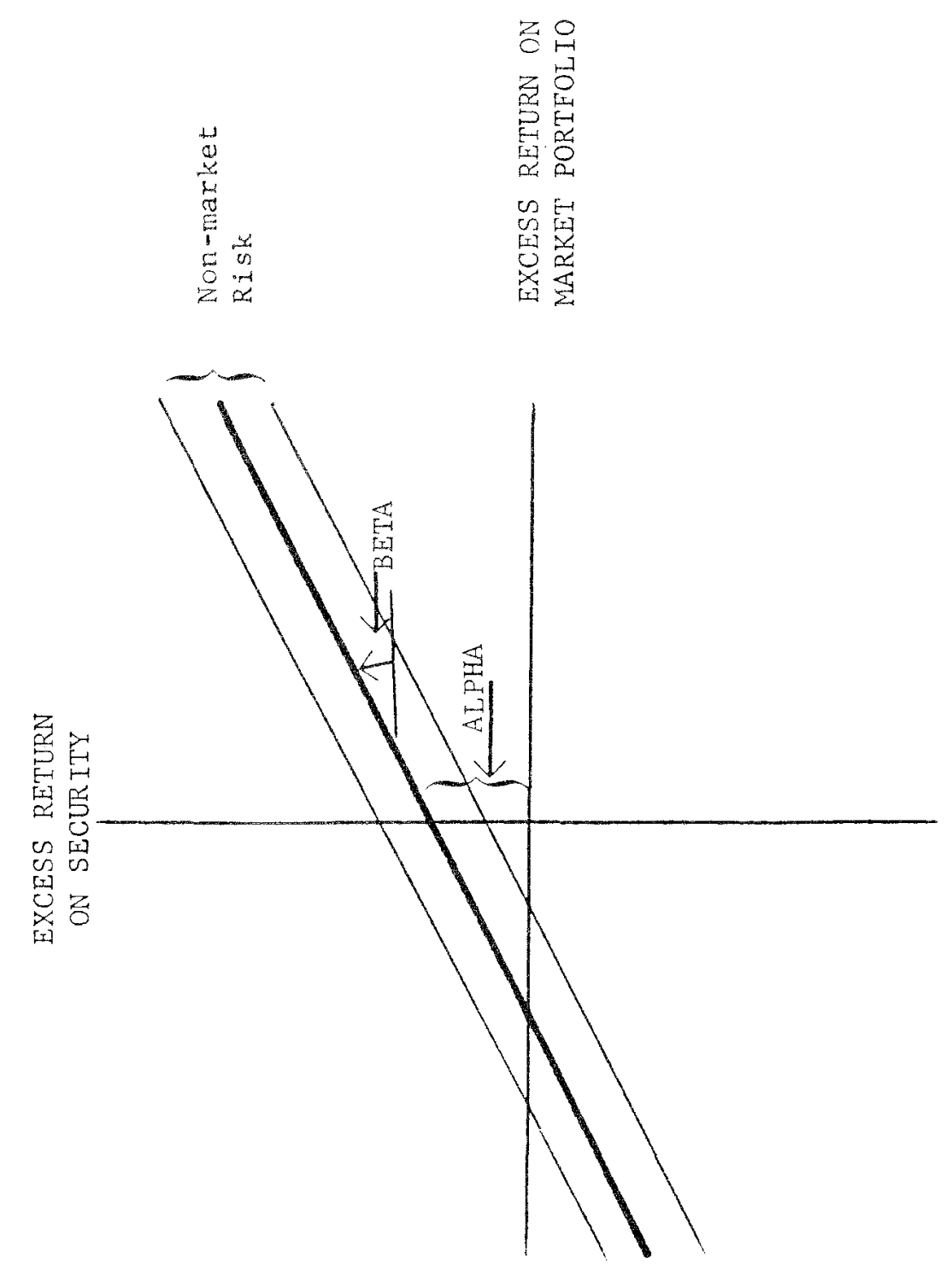

产 
2. Beta-the slope of the line: the extent to which the analyst believes the security's excess return will be affected by changes in the market's excess return. A value of 1 means that the stock is average; a value of less than 1 , that it is defensive; and a value of more than 1, that it is aggressive.

3. Non-market risk-the range around the line within which actual results are likely to fall. This is a measure of the analyst's feelings about all the uncertain factors that can affect a stock's return in addition to any influence the market may have. This includes "business risk" and "financial risk" as typically defined. And it is by far the larger part of total risk for most securities (about 70 percent on the average).

It is important to note that with this procedure the analyst is not required to make an assessment of the likely return on the market. Instead, he or she makes a best guess about each of a number of possible returns on the market (the characteristic line) and indicates his or her confidence in that set of guesses (the extent of non-market risk). The task of estimating the likely future of the market can thus be left to others.

Now, what of portfolios? Just as a security's prospects can be summarized with a characteristic line, so, too, can the prospects of a portfolio. In fact, given analysts' feelings about securities, the appropriate feelings about a portfolio can be calculated directly:

1. The alpha value for a portfolio's characteristic line is simply a weighted average of the alpha values of its component securities, with market values used as weights.

2. The beta value for a portfolio's characteristic line is simply a weighted average of the beta values of its component securities, with market values used as weights.

3. The non-market risk is more complex. In general, the more diversified a portfolio, the less its non-market risk. For the kind of portfolio held by the typical open-end mutual fund, as little as 10 percent of total risk may be attributable to non-market factors. 
This later point indicates the importance of both alpha and beta. While they tell relatively litule about the prospects for an individual security, they tell quite a bit about the prospects for a diversified portfolio. Thus it is important to get good estimates of alpha and beta for securities, since they are the components from which portfolio alphas and betas are formed.

Now let's turn to the matter of prices in an efficient market. We will deal with characteristic lines that reflect a "consensus" opinion of analysts. Let's begin with the possibility that there may be some bond that, like a treasury bill, is considered comple tely riskless. Imagine that it is priced to return more than a treasury bill. What will its characteristic line look like? Figure 2 provides an answer. No matter what the retum on the market, this bond will give the same positive excess return. Its characteristic line is thus horizontal and lies above the characteristic line for a treasury bill (which coincides with the horizontal axis).

How long could this situation prevail? Not very long, for arbitrage would swiftly be brought to bear. Investors would shun treasury bills and flock to buy this clearly underpriced bond. Prices would then change, under buying and selling pressure, until the two prospects were brought in to balance. The two characteristic lines would then coincide.

A similar situation can be described for a risky security. Consider the one whose characteristic line is shown in Figure 3. The consensus opinion is that this security has an alpha of $-2 \%$ (per quarter) and a beta of .8 , as well as some non-market risk. Is it underpriced, overpriced, or correctly priced?

Let's compare it with a treasury bill, whose prospects are shown by the flat characteristic line lying along the horizontal axis. Treasury bills are less risky, but if the market return is high enough, they will be out-performed by this security, It is not clear which is better.

Turn next to an investment in the market portfolio. Its characteristic line is a 45 -degree line through the origin, since the excess retum on the market portfolio (vertical axis) must, of course, always equal the excess return on the market portfolio (horizontal axis). The value of alpha must thus be zero, and the value of beta must be one. Moreover, as indicated earlier, the market portfolio has no non-market risk.

Now, is the hypothetical security in Figure 3 better or worse than investment in the market as a whole? The market portfolio's return is more sensitive to market swings and could underperform the security if 
:

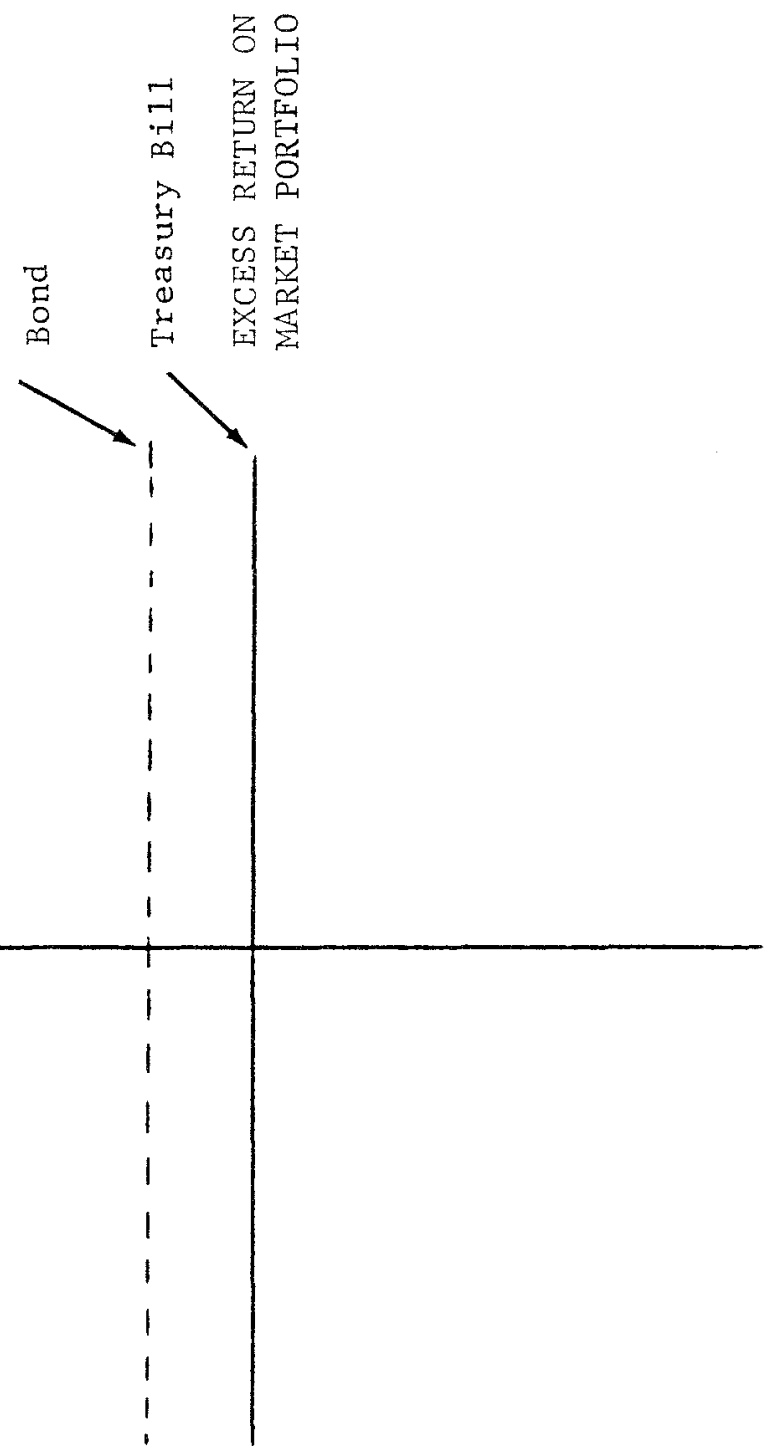




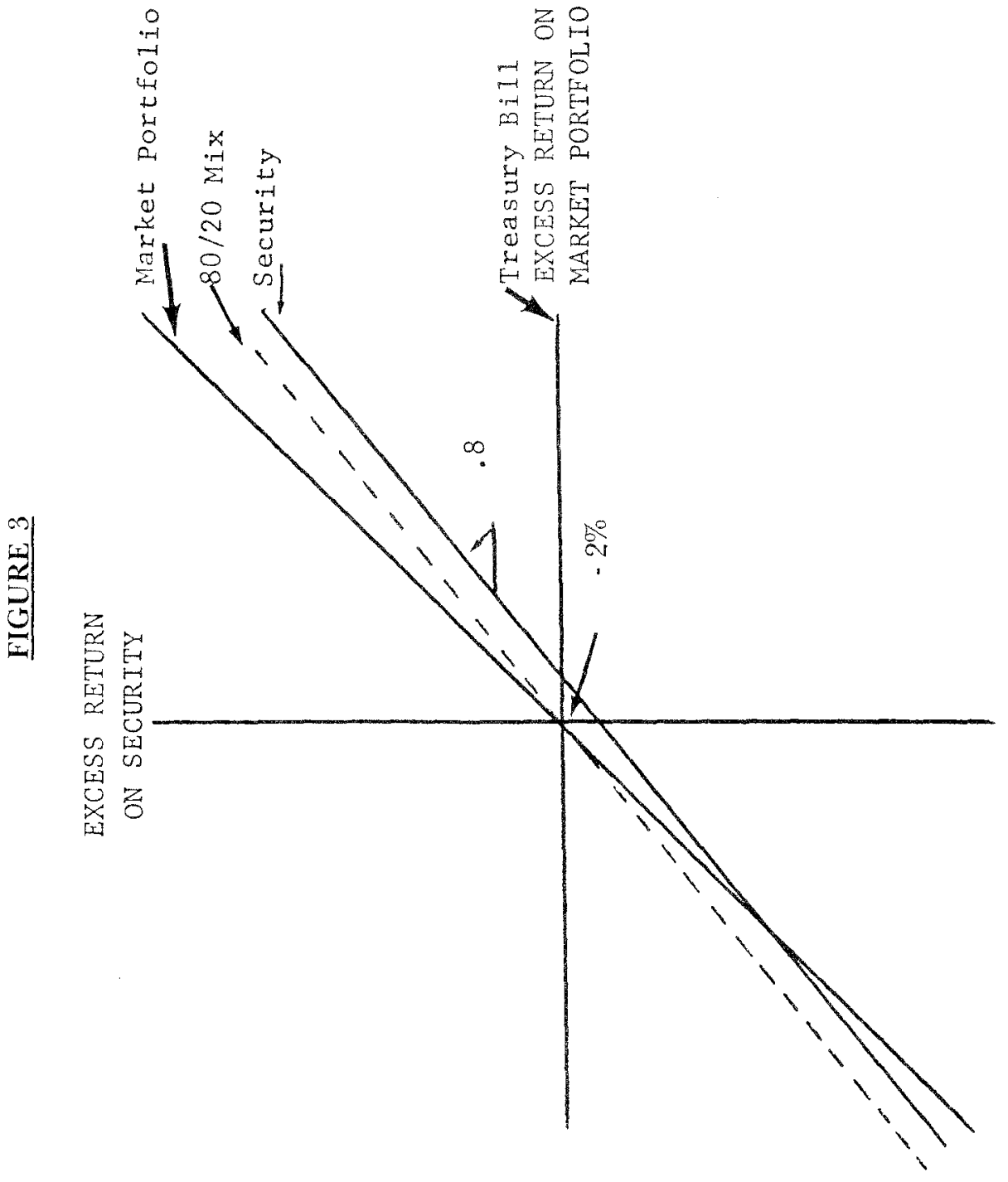


the market falls far enough. On the other hand, the market portfolio has no non-market risk. Here too, it is not clear which is better.

But there is another possibility. An investor could split his funds between the market portfolio and treasury bills in a manner designed to give the same level of market risk as that associated with the security. In this case the appropriate division would result in 80 percent invested in the market portfolio and 20 percent in treasury bills. This strategy would have a characteristic line passing through the origin (i.e., an alpha of zero) with a slope (beta) of .8 ; and it would clearly dominate the hypothetical security. Why? Because it would have the same level of market risk, no non-market risk, and offer an expected advantage of two percent per quarter, no matter what the market might do. In fact there is an interesting arbitrage strategy for a case such as this: (1) short the security and (2) go long the market portfolio and treasury bills. In any event, no analyst holding the opinion portrayed in Figure 3 would recommend holding the security.

The result is predictable. The security would be subjected to heavy selling pressure. Its price would fall, causing its characteristic line to rise.

A similar argument can be made if a security has a beta greater than one. In such a case, however, the appropriate strategy for purposes of comparison requires margined purchase of the market portfolio, the drawing down of an investor's savings account, or some other action of this type. To keep the analysis simple, it is assumed (perhaps unrealistically) that this can be accomplished at a cost equal to the return on a riskless security.

In either case, the conclusion is obvious. If the market is efficient, no security will be priced to have a negative alpha in the opinion of a well-informed analyst.

But what about the opposite possibility? Might a security have a positive alpha? Recall that the market portfolio as a whole must have an alpha of zero. But recall also that this is simply the weighted average of the alphas of the component securities. We have just established that in an efficient market, no security will have a negative alpha. Then how can the average value be zero? The answer is inescapable: every value must be zero.

We thus reach the denouement: in an efficient market, all securities will be priced so that in the consensus opinion, their characteristic lines pass through the origin-i.t., they will have alphas 0 ? zero. This is shown in Figure 4. 


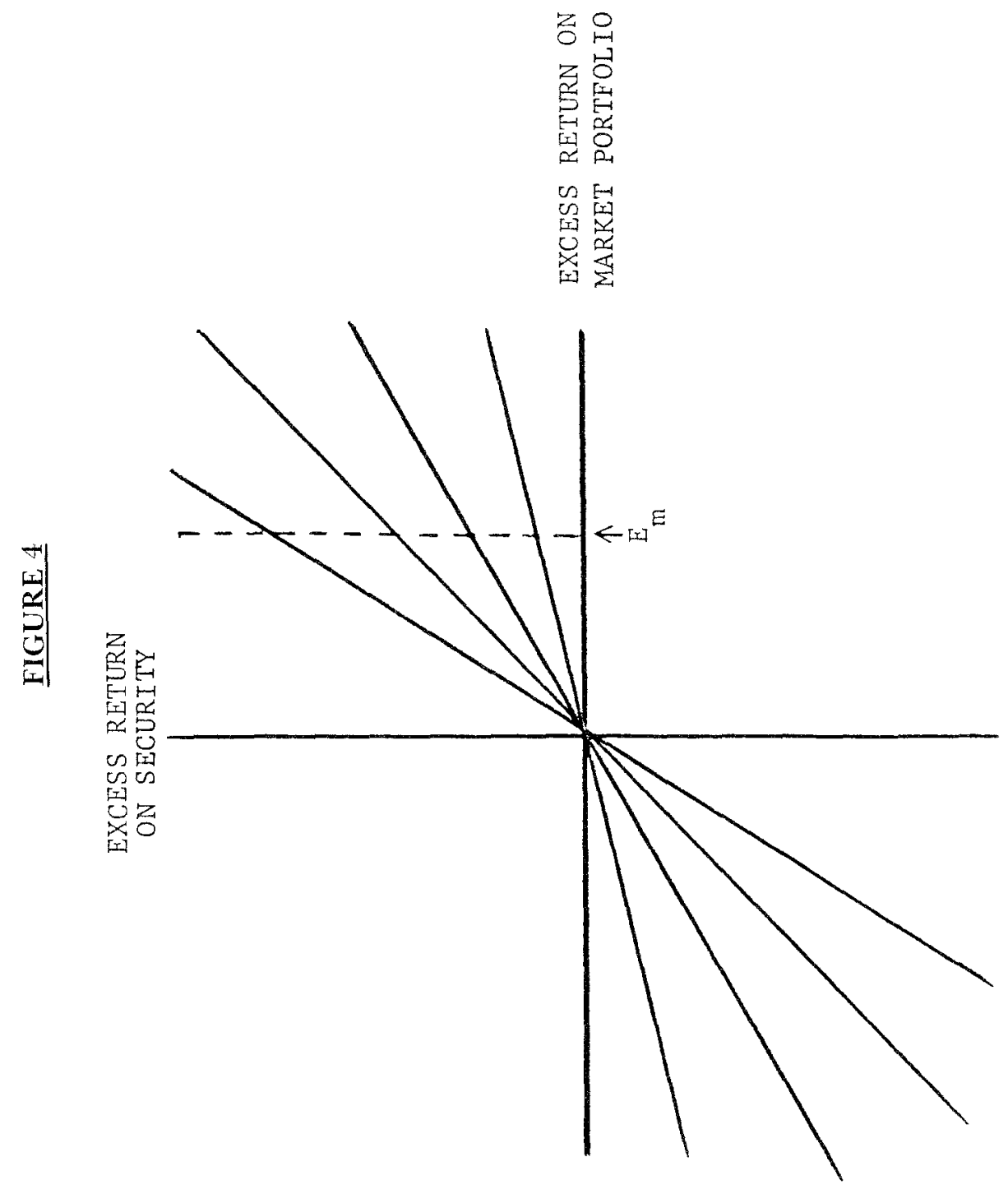


Now, what can we say about expected returns? First, the consensus opinion must hold that the market is expected to return more than treasury bills. Why? Because otherwise risk-averse investors would be advised to sell off risky investments, causing their prices to fall and their expected returns to rise. So we can conclude that the expected excess return on the market is positive: for example, $E_{m}$ in Figure 4.

What does this imply for the expected returns from securities? Figure 4 provides the answer. The higher a security's beta, the greater will be its expected retum. Treasury bills have a beta of zero and an expected excess return of zero. The market has a beta of one and an expected excess retum of $\mathrm{E}_{\mathrm{m}}$. A security with a beta of .5 has an expected excess return halfway between and so on. Thus, if we were to plot expected excess return versus beta, as in Figure 5, securities would plot along the line connecting treasury bills (point $T$ ) with the market portfolio (point M). This is called the market line. It says, quite simply, that (1) expected return and (2) risk (measured by beta) go hand in hand in an efficient market.

Why is beta a measure of risk? Figure 4 shows the reason quite forcefully. Although people expect the market to return more than treasury bills, in any given period it may do worse-perhaps very much worse. What happens then? The more sensitive stocks fall more. In other words, the greater a security's beta, the worse its actual performance is likely to be.

We have now reached the end of the exercise. The morals are fairly clear:

1. the most important single measure of risk concerns the extent to which a security will be affected by future market moves;

2. in an efficient market, this type of risk will be rewarded, on the average; the market is more likely to go up than down, and when it does, more sensitive stocks are likely to go up more than less sensitive stocks.

What does this mean for the security analyst? Perhaps most important, it suggests that he focus on the characteristic line of a security. All the tools of fundamental analysis can be employed in this connection, but it is important to direct them to the most crucial elements. 


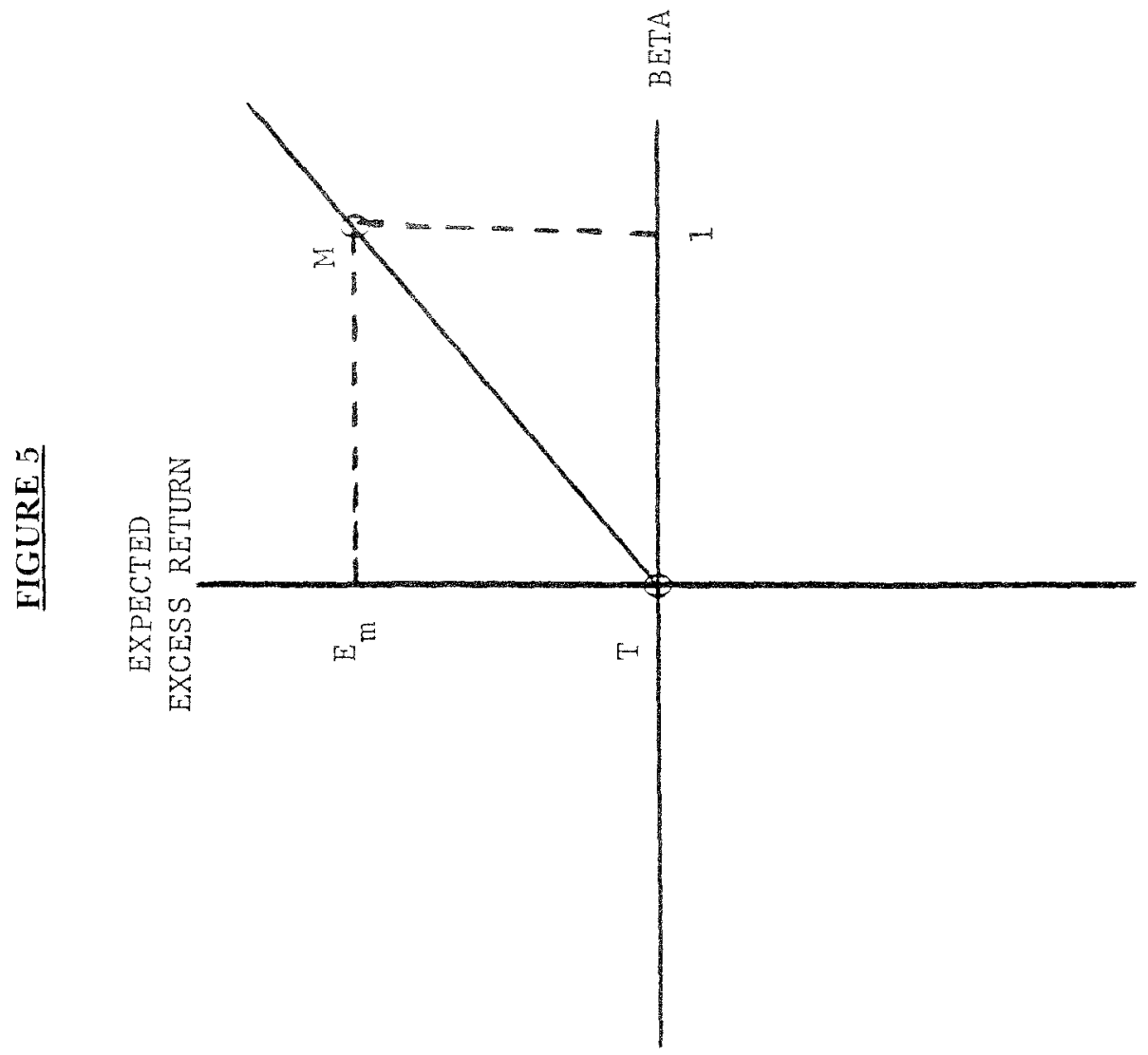


Analysis of past data can be helpful, but one cannot rely on it entirely. For example, it is useful to plot, say 60 months of data regarding actual returns on a security and some surrogate for the market portfolio, as in Figure 6, then fit an "empirical" characteristic line. The past value of beta, thus estimated, may be useful for predicting future beta, although it can usually be improved upon by considering some of the fundamental aspects of the company. On the other hand, the past value of alpha is virtually useless for predictive purposes. Recall that alpha indicates the extent to which a security is underpriced or overpriced. Whether a security was underpriced or overpriced in the past has almost no bearing on the question of whether it is underpriced or overpriced now. If predicting alpha is equivalent to finding underpriced and overpriced securities, no simple analysis of widely-available data is going to do the job in a market populated by large numbers of sophisticated and well-informed security analysts.

\section{The Single-Index Model}

The essence of the Capital Asset Pricing Model has been described. However, it seems desirable to discuss one additional issue before concluding. For purposes of investment decision-making, it is almost essential to adopt some simplifying assumptions about the relationships among securities. One rather extreme procedure of this sort involves the adoption of a single-index model. Since the approach has a number of attributes in common with the results of the Capital Asset Pricing Model, people sometimes assume that the two are completely equivalent. They are not, as this section will show.

This basic equation of a single-index model can be written as follows:

$$
\widetilde{R}_{i}-p=\alpha_{i}+\beta_{i}\left(\widetilde{R}_{m}-p\right)+\widetilde{c}_{i}
$$

where: $\quad \widetilde{R}_{\mathrm{i}}=$ the return on security $\mathrm{i}$

$\mathrm{p}=$ the pure interest rate

$\widetilde{\mathrm{R}}_{\mathrm{m}}=$ the return on a market portfolio (or any index)

$\alpha_{i}=$ the security's alpha value

$\beta_{i}=$ the security's beta value 

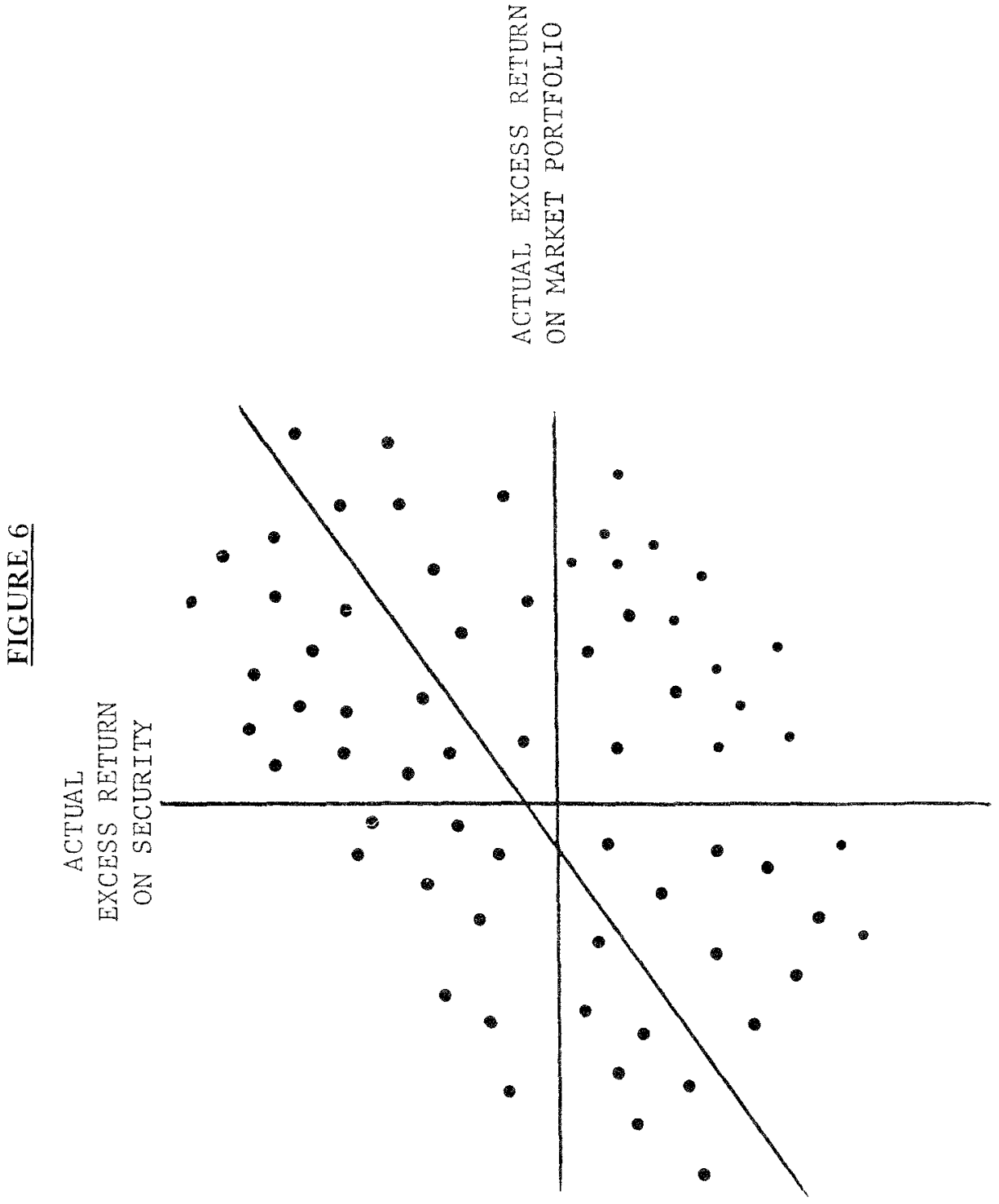


$$
\begin{aligned}
\widetilde{\mathrm{c}}_{\mathrm{i}}= & \text { the difference between the excess return on } \\
& \text { the security and that predicted, given its alpha } \\
& \text { and beta and the excess return on the market } \\
& \text { portfolio. }
\end{aligned}
$$

Tildes (squiggly lines) have been placed over the values that are generally not known in advance-i.e., the variables subject to uncertainty.

As written, this is simply the characteristic line of the Capital Asset Pricing Model. Without loss of generality, one can also hold that the expected value of every $\widetilde{c}_{i}$ is zero. The Capital Asset Pricing Model adds to this the assertion that all values of alpha are also zero. And that is all that the Capital Asset Pricing Model adds.

This leaves open the question of interrelationships among security returns other than those attributable to common relationships with the market as a whole. The usual normative application of the single index model makes an extremely strong assumption on this score. It assumes that no such relationships exist. This is equivalent to assuming that all the values of the $\widetilde{c}_{i}$ 's are uncorrelated with one another. Both common sense and empirical evidence suggest that this is not so. Practical applications using this assumption must therefore be considered carefully. But that is another subject. The important point is that the Capital Asset Pricing Model makes no such assumption. Evidence against this aspect of the single index model is not evidence against the Capital Asset Pricing Model.

\section{Conclusions}

Modifications and extensions of the basic Capital Asset Pricing Model described here are being made almost daily. Moreover, a great amount of empirical data has been used to estimate the extent to which the real world really does conform to the associated implications. Not surprisingly, a number of issues remain cloudy. However, there is increasing agreement that capital markets in the United States and most other developed countries are highly (if not completely) efficient. Investment analysis that fails to take this into account seems likely to eventually pay the price in inferior performance. 


\title{
EFFICIENT CAPITAL MARKETS-A PRACTITIONER'S VIEW
}

\author{
Edmund A. Mennis, C.F.A.
}

Several alternatives are available to a discussant. One is to take an adversary position and criticize points made by the speaker. Another alternative is to raise questions, to seek clarification of issues, to discuss the applicability of the research and perhaps suggest ideas for future research. I prefer the second approach and will try to present the problems of this practitioner, at least, in understanding and making use of the academic research on efficient capital markets.

At the outset it can be stated that a good deal of the academic research has contributed significantly to our understanding of financial markets and can be accepted by the practitioner. The random walk theory, which states that future stock price movements are independent of past price movements and that past prices cannot be used for predictive purposes, has very strong statistical support and can be accepted by most reasonable people.

Subsequent extensions of the random walk have led to the so-called "semi-strong" and "strong" forms of the efficient market hypothesis. This hypothesis suggests that it is fruitless to examine public information in order to obtain superior rates of return, because all that is knowable about stock prices is embedded in the current price of the stock and therefore capital markets are "efficient". Because information is both knowable and immediately reflected, a serious question is therefore posed as to the usefulness of not just technical analysis, but of fundamental analysis as well.

The evidence to support the "semi-strong" form relates essentially to the speed of adjustment to new information. Lorie and Hamilton present three studies in support of this thesis. The first indicates that stock splits do not assure an unusual profit for investors. The second piece of evidence suggests that secondary offerings depress the market price of a stock because such offerings imply that knowledgeable people are selling the stock. The third study suggests that unusual 
earnings increases are anticipated in the price of the stock before the company's earnings for the year are finally reported.

A practitioner would not be surprised by these findings nor would he find them difficult to accept. Cutting a piece of pie in to more pieces does not make a bigger pie. A practitioner realizes that a large secondary offering may be based on information that he does not have and should be examined carefully. Finally, if an analyst does his job correctly, he should not be surprised by a substantial increase in earnings of a company before the annual results are released to the press two to three months after the end of the year. Consequently, the "semi-strong" form, which argues that certain types of public information do not produce superior investment results, seems reasonable.

However, the other category of the efficient market hypothesis, the so-called "strong" form, presents a professional investor with some problems. This form asserts that stock prices reflect not only what is generally known, but also that superior results are not obtainable from original insight or from other types of fundamental analysis. Most professionals would concede that obtaining superior results from original insights is difficult. A large number of analysts are constantly engaged in ferreting out information or devising new ways of looking at the same information. Moreover, frequent and rapid communication among analysts facilitates these adjustments and does have a tendency to increase their rapidity. As a matter of fact, these efforts on the part of analysts are cited by believers in the efficient market hypothesis as the reason for concluding that markets are efficient.

The evidence presented for the strong form is based on an examination of investment results of a number of institutional investment organizations. These studies indicate that the performance of a large group of mutual funds has not outperformed market averages. Other studies have indicated similar results for other large institutional portfolios, such as pension funds and bank common trust funds. Still other studies have shown that, although some funds are more volatile than others, on a risk-adjusted basis, the funds do not on average outperform the market.

The evidence is rather substantial. However, to a practitioner at least, it does raise some questions as to whether it is conclusive. The most obvious point is that insitutional investors dominate the stock market, and therefore it is hard to achieve above-average results on average. 
The next question is whether some institutions produce consistently superior results. On this question, the evidence is considerably less satisfactory to conclude that some investment organizations, at least, do not perform either consistently well or consistently poorly relative to the market over a period of time. Most of the evidence deals with annual data and does not indicate perform ance during various market cycles. Moreover, the evidence deals with organizations rather than with individual managers or investment teams, and anyone familar with the great mobility of personnel in the investment field might well request further research in this area.

Aside from the evidence presented on this point, the question still remains: Is it possible to achieve unusual returns? The efficient market hypothesis answers this question in the negative, because information is presumably available quickly to all participants and is therefore quickly discounted in the market. To this practitioner at least, this conclusion requires considerably more support before it can be accepted.

Information is objective in nature but the interpretation by the recipients is not necessarily uniform. Even assuming rapid dissemination, the recipient may have different experience, different investment objectives and a different investment time horizon than another investor. The action taken by a short-term oriented mutual fund manager in response to a near-term disappointment in corporate earnings may be different from that of a trust investment officer who has a much longer time horizon and who may find as a result of the same information a buying opportunity he seeks in a stock he has thus far considered overpriced.

Another point to be made is that all investors do not have simultaneous access to the same information. Some of them may receive it on the broad tape, others may receive it in next day's Wall Street Journal. Still others may get it in an abbreviated form, if at all, in the local newspaper, and some may wait until the quarterly or annual report of the company is finally sent to them. Not only is access not simultaneous, but the conviction or belief of the investor with respect to the information may vary. Some investors may take the company statement at its face value, some may require more information to make a decision, and different interpretations are certainly possible. In addition, not all investors take action simultaneously. A mutual fund manager, upon receipt of the information, may instantly reach for the phone to his trading desk, whereas another portfolio manager may defer a decision until he locates more information or consults with his 
client. Consequently, it secms more reasonable to expect that a particular piece of information may not be universally received, interpreted and acted upon within a relatively short period of time, and the market consequently may not be as efficient as academic writers believe. Failure of institutional investors as a group to achieve above-average performance is hardly satisfactory evidence to refute these observed actions of investors. Should not further work be done to explore these areas?

Aside from the argument of the speed and interpretation of information, the efficient market hypothesis holds that, al though there are many independent estimates of a stock's value, the correct price of a stock will have a mean equal to the correct value because some people will overestimate and others will underestimate value. These over- and under-estimations will oflset each other and force the market price toward the mean of the estimates. It is difficult to agree with this conclusion. The price of a stock is not set by the estimates of all of those who make estimates but rather by the estimates of buyers and sellers.

The buyer is viewing any particular stock in the context of all of the stocks that he might add to his portfolio as well as those that he owns. He presumably has some decision model for selection based on his investment objectives and his desire to improve the performance of the account. He has presumably prepared a buy list of securities or would buy from those his research stafl has submitted to him, and this list will probably contain a larger number of securities with overestimated returns than if he were selecting stocks at random.

The sellcr, on the other hand, is dealing with a different universe because he is reviewing only those stocks that he already owns. He may be relying on his own estimates or those of his research staff, but, here again, a bias probably exists in the selection process because he lists only those stocks he owns in relative order of attractiveness. The market price of the stock is determined by the balance between these two groups of buyers and sellers acting at the margin, not by the balance between the estimates of the universe of investors and analysts. The issue becomes even more complex should buyers and sellers be considering investment alternatives other than just stocks. Do we not need research to determine the impacts of these two groups on market prices, and whether their estimates of values on average result in an efficient market? 
We now turn to the second part of the discussion which deals with the construction of efficient portfolios. I will pass over in this discussion such real world problems as tax considerations, transaction costs, liquidity problems, and portfolio constraints set by law or customer choice.

Briefly summarized, current theory holds that the stock market is efficient and that stock prices reflect fully and virtually instanteously what is knowable about the prospects of companies whose stocks are traded. Consequently, it is useless to attempt to select securities considered undervalued, because current price reflects value. My previous comments have indicated why I have difficulty accepting these assumptions.

Granting these assumptions, however, the portfolio manager is expected to construct a well-diversified portfolio having a greater-or less-than-market risk depending upon the portfolio manager's view of the market and the customer's willingness to accept risk. In the strictest academic sense, the percent of the portfolio committed to the market as a whole is varied as market and risk assumptions vary, borrowing or lending at the risk-free rate as necessary. Risk is measured by the historical volatility of a stock relative to the market, or its so-called beta value. Successful portfolios are therefore achieved by diversifying away specific risk and exposing the portfolio only to the market risk.

One of the assumptions made is that investors are risk-averse and therefore should seek to diversify away the specific risk of a security. If investors were totally risk-averse they ought to confine their investments to riskless securities. My own observation suggests that they seek to expose themselves to risk where they believe the opportunity exists for higher returns than can be obtained from riskless investments. A more appropriate statement might be that investors seek to avoid investments that are not expected to provide more than a risk-free return and to expose themselves to risks where they think they can obtain a higher return.

Elsewhere I have discussed in more detail my own approach to a method of exposing a portfolio to specific risk and return and will mention it here only briefly. A portfolio manager is primarily in terested not in the absolute return but the relative return that can be obtained from alternative investments. An integrated approach to portfolio management is recommended, moving from economic projections, both long and short term, to interest rate expectations, profit estimates, earnings and probable multiples on stock market averages, and finally 
to industry studies, company analyses and stock selection. A portfolio should be deliberately exposed to those economic areas where market returns are expected to be better than average and to avoid those where the expected returns are expected to be lower. Selection of stocks within this framework should be concentrated on both long- and short-term analyses of the level, growth and stability of earnings and an appropriate valuation of these earnings in the assumed economic and market framework. In this approach, the critical point is the exposure of the portfolio to attractive sectors of the market rather than to the selection of specific securities. Nevertheless, careful security analysis should provide an incremental return by the selection of stocks at prices that appear to be different from intrinsic value.

By use of an integrated approach-by integrating economic analysis with market analysis, industry exposure and company selection-portfolios can be constructed that differ from the structure of the market and certainly from consensus beliefs. With so much of a stock's performance influenced by the specific risk of the security rather than by market risk, it seems inappropriate not to attempt to take advantage of the opportunities afforded by good security analysis. To the best of my knowledge, academic evidence thus far has not proven that unique prediction of the specific risks of industries and stocks is an impossible task.

As an aside, a comment can be made here about the conventional types of security reports that are most frequently prepared in the investment community. These reports ordinarily contain a rather lengthy discussion of the company and its various parts and may relate the position of the company in the industry in which it operates. Unfortunately, earnings estimates are usually confined to the next few calendar quarters or the calendar year, with little or no discussion devoted to the longer term earning power of the company. Frequently, earnings estimates are the company's estimates rather than the analyst's. Even more serious, a company is usually treated as if it existed in a vacuum rather than operating in an economic environment that could have a significant impact on earnings. Worst of all, little or no effort is devoted to discussing value estimates of the stock or to discussing why a stock might be considered over-or under-valued. The paucity of analysis in most security reports could well explain the inaccuracies of analysts' forecasts as uncovered by academic researchers. 
Turning now to the portfolio approach referred to in the capital asset pricing model, some further difficulties are encountered by the practitioner. The first is that risk is equated to the historic volatility of the stock. Historical volatility is suggested as a measure for future volatility, although on occasion it is suggested that perhaps security analysts can indicate when future volatility might be different.

The first problem the practitioner encounters is the assumption that volatility is an acceptable measure of risk without reference to price. As an example, in January of 1973, IBM, one of the few high quality first-tier grow th stocks then dominating the stock market, was selling at about 35\% times its estimated earnings for 1973. In May of 1974, IBM, at 225 is selling a little over 18 times its estimated earnings for this year. Whatever measures of historical volatility are used, it is unlikely that the volatility of IBM has changed materially during the past 15 months. A practitioner might well consider IBM riskier in January of 1973 and significantly less risky today. It is difficult for him intellectually to accept the conclusion that IBM should be considered of relatively equal "riskiness" at each of these time periods because its historical volatility was about the same. Can volatility be an acceptable measure of risk without consideration of current price?

Another problem is using betas as measures of risk because of the various ways by which they are computed. It is well known that various services providing beta information on particular stocks do not produce the same figures for each company. These are not differences of small magnitude. For example, in one series of computations, Bethlehem Steel is shown to have a beta of 1.52 and in another a beta of .78 . This hardly is of assistance to a portfolio manager who is attempting to determine the impact of Bethlehem Steel upon the volatility of his portfolio! What guidance can be given to a portfolio manager for his selection of the appropriate set of beta values to use?

Another issue with respect to betas is their stability over time. Some evidence suggests that stocks with betas below and above one have a tendency to drift toward one and presumably some statistical adjustments have to be made for that factor. Other evidence suggests that betas differ for the same industries and presumably for the same stocks over various time periods. Another problem in the use of betas is the extent to which the movement of the stock historically has been influenced by the specific risk of the stock and the extent to which it is influenced by market movements. The $\mathrm{R}^{2}$ and the non-market risk varies considerably from stock to stock, although it is conceded that 
this factor decreases significantly in importance when a group of stocks are assembled in a portfolio. Nevertheless, should a portfolio manager avoid all stocks that are not highly correlated with the market? To what extent can the portfolio manager rely upon historical or projected betas in making portfolio shifts, hoping that this will improve his portfolio performance?

One final difficulty with the capital market pricing model still remains. The determination of the future market level becomes critical in order to determine whether greater or lesser risk should be assumed in a portfolio. Predicting future market levels can indeed be a hazardous occupation, as anyone who has tried to do it professionally over a period of time well recognizes. The portfolio manager might follow the recommendations of the academician quite carefully and construct portfolios that should perform somewhat better than the market, but can he or his organization get some guidance in the factors that influence the market, both long- and short-term?

I have tried in this discussion to raise a number of questions that have made acceptance of much of the academic research difficult for a practitioner. I do not mean to imply that the work done should be disregarded or that portions of it cannot be used successfully and beneficially by professional money managers. However, I do suggest that more consideration of the practical problems of money management and additional research are needed. Both the academician and the practicing financial analyst should work together more closely in an attempt to serve their customers and the capital markets more effectively. 


\section{REFERENCES}

1. Frank E. Block, "Time Horizon", Financial Analysts Journal, Vol. 28, No. 5 (September-October 1972), pp. 30-31, 60-62.

2. "Elements of Portfolio Construction", Financial Analysts Joumal, Vol. 25, No. 3 (May-June 1969), pp. 123-129.

3. James H. Lorie and Mary T. Hamilton, The Stock Market-Theories and Evidence, (Homewood, Illinois: Richard D. Irwin, Inc., 1973).

4. Edmund A. Mennis, "An Integrated Approach to Portfolio Management", Financial Analysts Joumal, Vol. 30, No. 2 (March-April 1974), pp. 38-46,86.

5. William F. Sharpe, "Diversification and Portfolio Risk", Financial Analysts Joumal, Vol. 28, No. 1 (January-February 1972), pp. 74-79.

6. —_ "Efficient Capital Markets with Risk", Research Paper No. 71, Graduate School of Business, Stanford University, March 1972).

7. J. L. Valentine, Financial Analysis and Capital Market Theory, (Charlottesville, Va. Financial Analysts Research Foundation, $1974)$. 


\title{
TESTS OF CAPITAL MARKET THEORY AND IMPLICATIONS OF THE EVIDENCE
}

\author{
Michael C. Jensen
}

This paper will review the empirical evidence on the market model and discuss its implications for security analysis. To begin this discussion, let me point out that the Market Model, or what Sharpe [1963] originally called the diagonal model, and the Capital Asset Pricing Model are very distinct models. Neither one depends in any way on the other. Many people confuse these two models but they refer to quite different concepts and it is well to keep the distinction clearly in mind. This paper will consider the major characteristics of the Market Model, provide some illustrative examples and briefly summarize the evidence. A Technical Paper prepared in connection with this paper considers the major characteristics of the Asset Pricing Model and a discussion of the theoretical and empirical content of the Two Factor Model.*

\section{THE MARKET MODEL}

\section{The Assumptions and Interpretation of the Market Model}

The market model hypothesizes that we can represent the returns on an individual security (or portfolio) as a linear function of an index of market returns. That is, if we let:

$$
\begin{aligned}
\mathrm{R}_{\mathrm{jt}}= & \begin{array}{l}
\text { Returns on security } \mathrm{j} \text { for period } \mathrm{t} \text { including both } \\
\text { dividends and capital gains expressed as a fraction of the } \\
\text { beginning of period price. }
\end{array} \\
\mathrm{R}_{\mathrm{Mt}}= & \begin{array}{l}
\text { Returns on a market index for period } \mathrm{t} \text { including both } \\
\text { dividends and capital gains expressed as a fraction of the } \\
\text { beginning of period price. }
\end{array}
\end{aligned}
$$

Copies of Dr. Jensen's complete research paper may be obtained from: The Financial Analysts Research Foundation, University of Virginia, Post Office Box 3668, Charlottesville, Virginia 22903. Please include payment of $\$ 3.00$ with your order. 
Then the market model says that the relationship between the returns on security $\mathrm{j}$ and the market index is given by

$$
R_{j t}=a_{j}+\beta_{j} R_{M t}+e_{j t}
$$

where $a_{j}$ and $\beta_{j}$ are constants specific to security $j . e_{j t}$ is a random error term specilic to the $j^{\prime}$ th security for period $t$, and is assumed to be uncorrelated with the market returns and the error terms for all other securities. I emphasize the fact that there is no theory behind the market model given by (1). It is simply a statement about the empirical relationship between security and market returns and tells us nothing about what causes retums to be what they are in any period. It hypothesizes only that there is a systematic linear association between the returns on individual securities and the market index, and empirical tests confirm this characteristic of the model.

An example of the relationship between the monthly returns on Xerox and the market returns over the $107 \mathrm{mon}$ th period from August 1961 to June 1970 is given in Figure 1. Each point denotes the return earned on Xerox for some month in this time interval and the corresponding return earned that month on the market index. The market index retums were calculated as the average return on all securities listed on the NYSE for each month during this period. ${ }^{1}$ (Single data points are represented by an asterisk and multiple data points at the same location are plotted with a numeral representing the number of points at that location. $M$ denotes the point of means.) The estimated regression or "characteristic" line given by equation (1) with intercept, $a=.018$, and slope, $\beta=.97$, is drawn on the scatter diagram. (The standard errors of estimates of the coefficients and the correlation coefficient, which for Xerox is .488 , are given in Table 1 along with those for several other securities.)

The regression or characteristic line of the market model describes what return Xero $x$ will earn on the average given any particular return on the market index. The slope coefficient $\beta$, the slope of the line drawn in Figure 1. (which for Xerox is .97) is often called the measure of "volatility" or "market sensitivity" or "systematic risk." In this case it tells us that when the market return for a given month is $1 \%$ above its mean, the returns of Xerox will on the average be $.97 \%$ higher than its mean return and vice versa when the market retum is $1 \%$ below its mean. Obviously, the return on Xerox is not always exactly $.97 \%$ above 


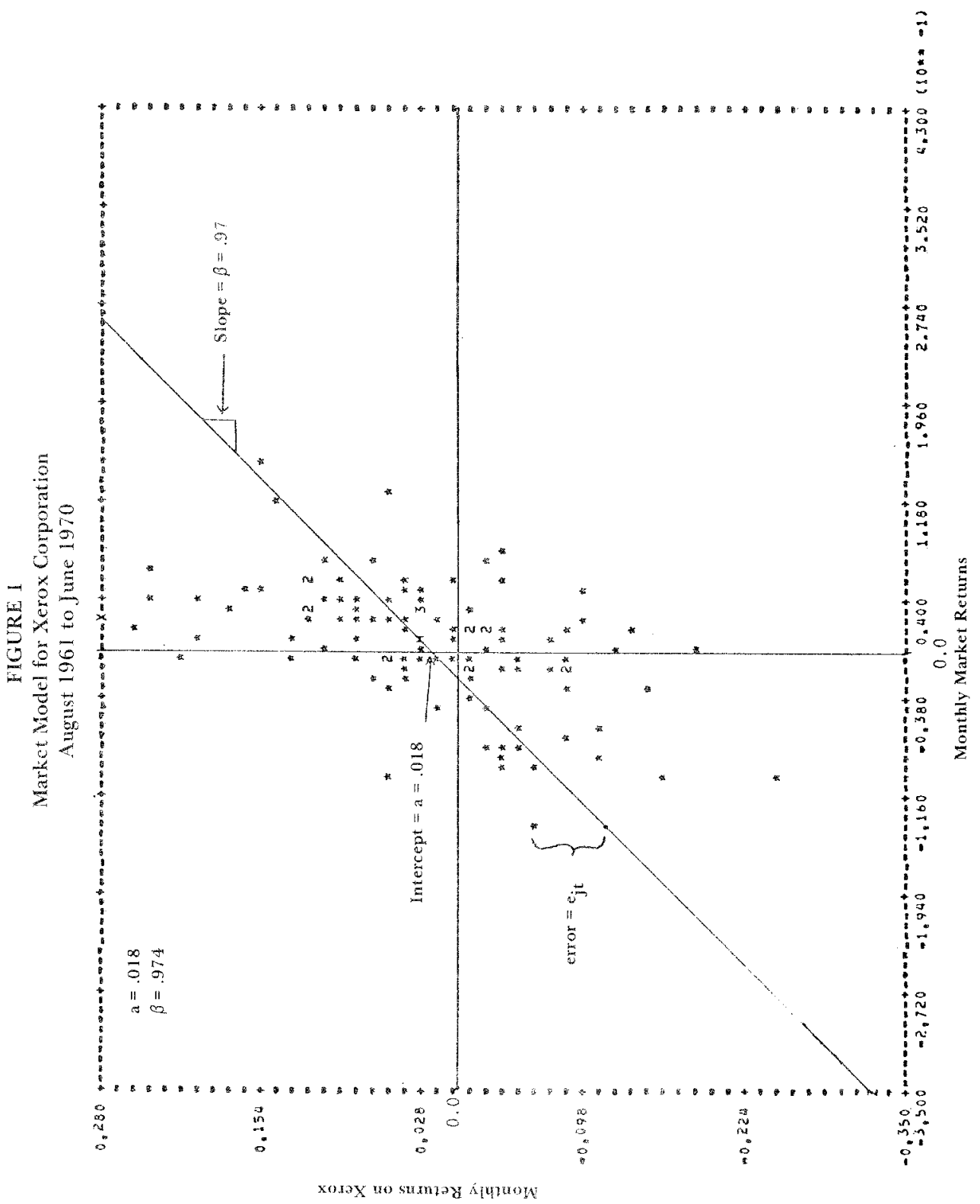


its mean in such months, since if that were true all the points in the graph would lie exactly on the regression line. The vertical distance between each point and the regression line represents the error term, $\mathrm{e}_{\mathrm{jt}}$, in equation (1)-also illustrated in Figure 1. The intercept, $\mathrm{a}=.018$, tells us that we expect Xerox to earn 1.8 percent per month on the average when the retums on the market are zero. These coefficients, thus, have very simple and intuitive interpretations. Furthermore, we also know that the average intercept and slope coefficients for all securities are respectively zero and one given our definition of the market index. ${ }^{2}$ Thus, securities with betas greater than one are more volatile or more sensitive to general market conditions than the average and vice versa for securities with betas of less than one. The market model given by equation (1) can be applied to bonds as well, and Sharpe [1973] shows that the beta for bonds over the period 1946-1971 was .252. He used quarterly returns on the Keystone B-2 bond fund and the Dow Jones Industrial Average to obtain these estimates.

Several other examples of estimates of the Market Model for securities with widely different characteristics are given in Figures 2, 3 and 4. The time periods used are July 1960-June 1970 or the period of listing on the NYSE, whichever is shorter. The securities and their regression statistics are also given in Table 1 . As the reader can see the utility and gold stocks represented by Consolidated Edison and Homestake Mining are far less sensitive to market movements (i.e., low betas) than Xerox, and Teledyne is far more sensitive (i.e., high beta). In addition, Figure 5 portrays the market model for a portfolio made up of an equal dollar investment in the following 17 stocks, all of which are contained in the Dow Jones Index:

$\begin{array}{ll}\text { U.S. Steel } & \text { Eastman Kodak } \\ \text { General Electric } & \text { Union Carbide } \\ \text { International Paper } & \text { Allied Chemical } \\ \text { American Brands } & \text { Sears, Roebuck } \\ \text { General Foods } & \text { General Motors } \\ \text { Procter \& Gamble } & \text { Goodyear } \\ \text { Texaco } & \text { International Harvester } \\ \text { International Nickle } & \text { Owens-lllinois } \\ \text { Johns-Manville } & \end{array}$

The intercept and beta for this portfolio are respectively .001 and .672 . The major difference between the model as applied to the portfolio and 


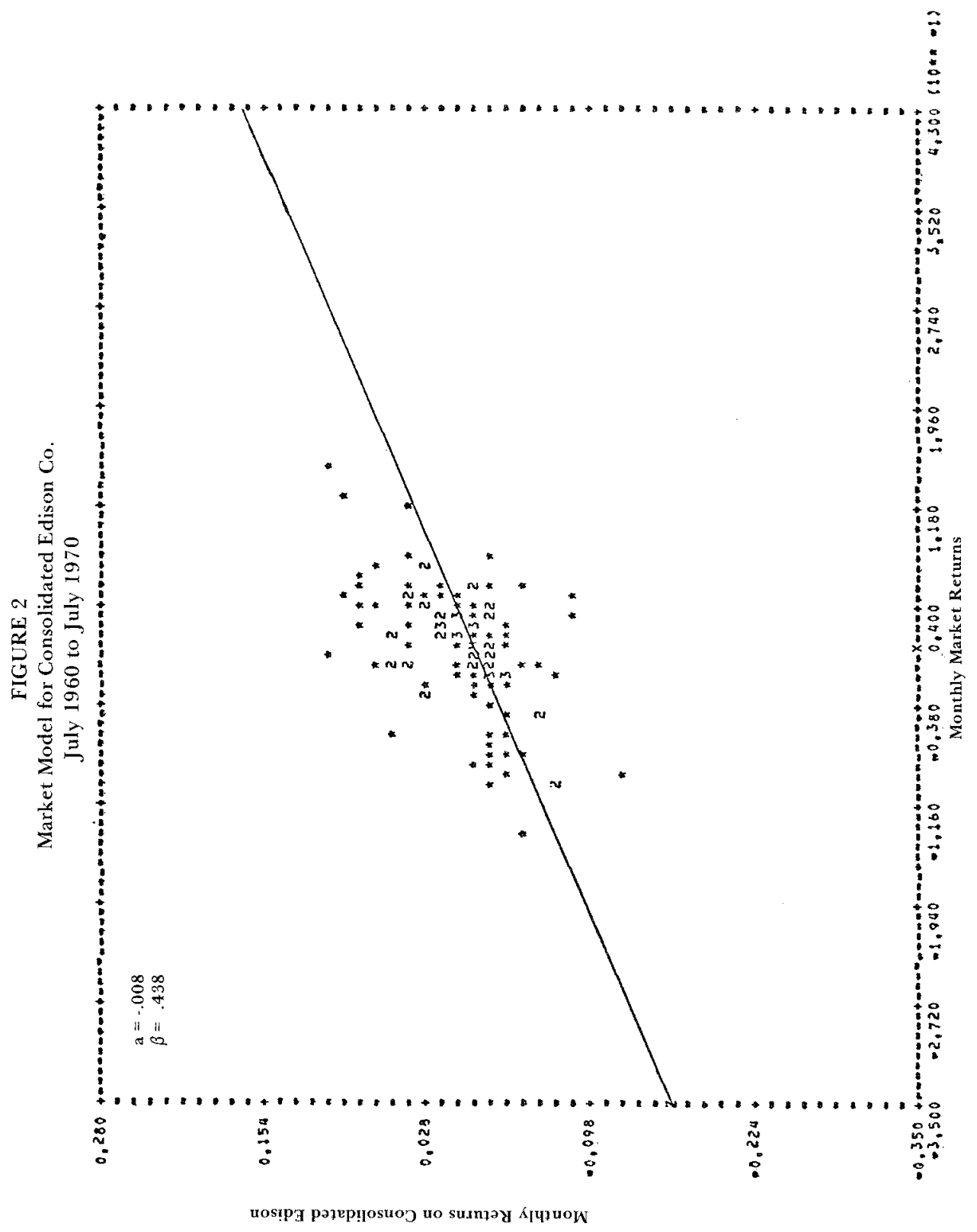




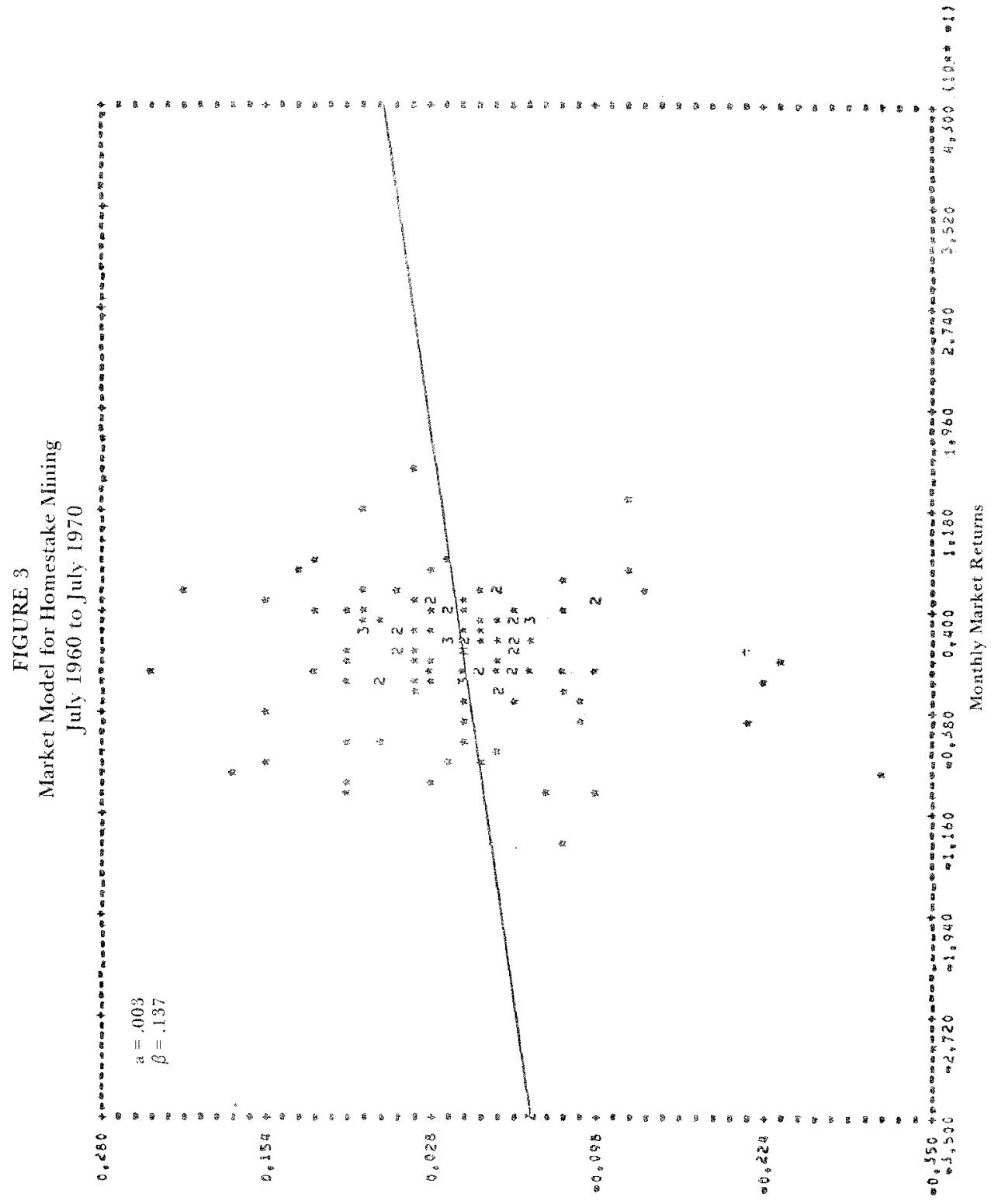

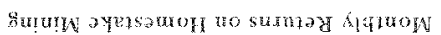




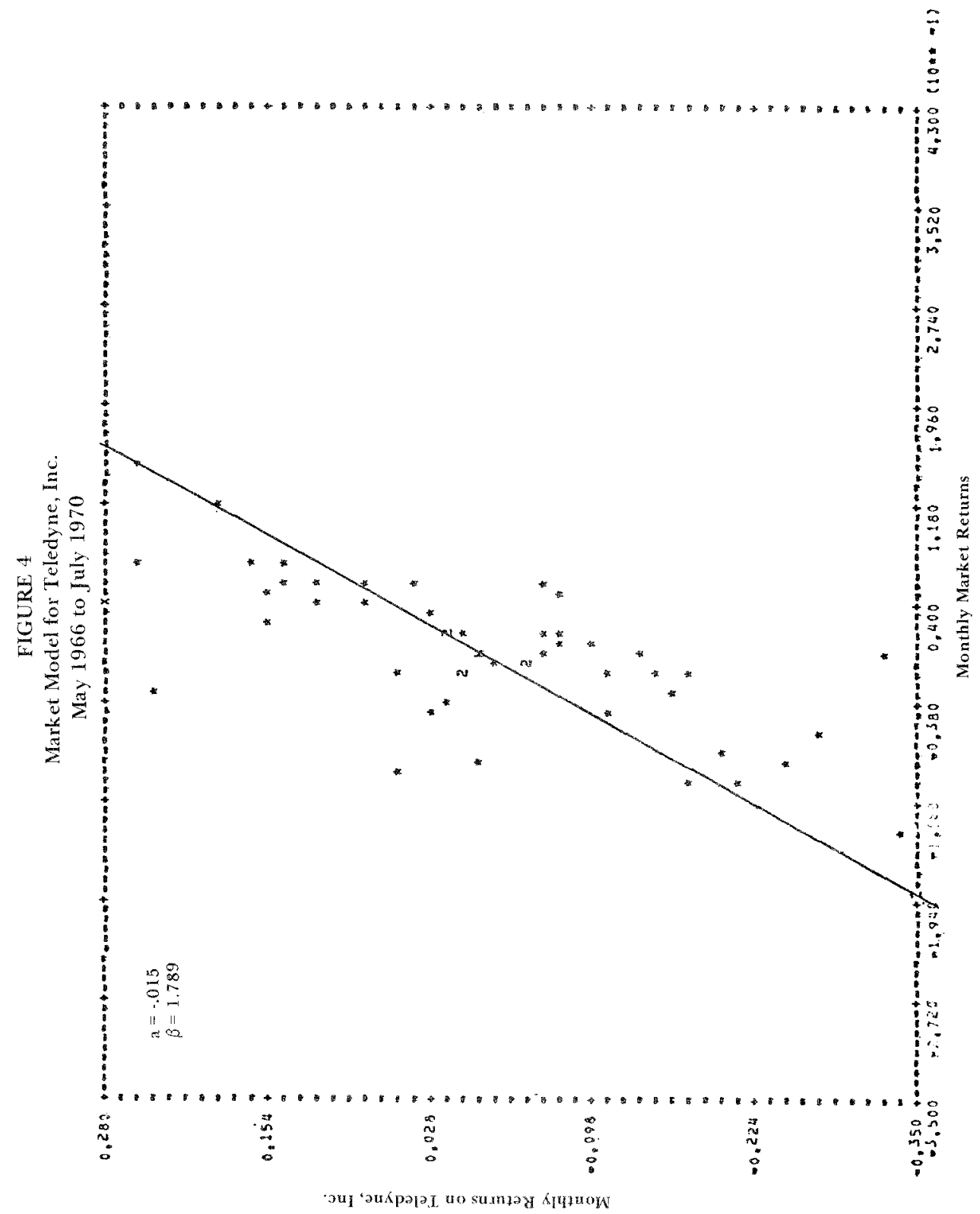




\section{TABLE 1}

Illustrative Regression Estimates of the Market

Model Obtained from Monthly Data

$$
\mathrm{R}_{\mathrm{jt}}=\mathrm{a}_{\mathrm{j}}+\beta_{\mathrm{j}} \mathrm{R}_{\mathrm{Mt}}+\mathrm{e}_{\mathrm{jt}}
$$

(Standard error of estimate in parentheses.)

\begin{tabular}{|c|c|c|c|c|}
\hline "Security" & $\begin{array}{c}\text { Intercept } \\
a_{j} \\
\end{array}$ & $\begin{array}{c}\text { Slope } \\
\beta_{j} \\
\end{array}$ & $\begin{array}{l}\text { Correlation } \\
\text { Coefficient }\end{array}$ & $\begin{array}{c}\text { Time Period } \\
\text { and Sample } \\
\text { Size }\end{array}$ \\
\hline Xerox & $\begin{array}{l}.018 \\
(.008)\end{array}$ & $\begin{array}{l}.974 \\
(.170)\end{array}$ & .488 & $\begin{array}{c}8 / 61-6 / 70 \\
107\end{array}$ \\
\hline Consolidated Edison & $\begin{array}{l}-.008 \\
(.007)\end{array}$ & $\begin{array}{c}.438 \\
(.140)\end{array}$ & .277 & $\begin{array}{c}7 / 60-6 / 70 \\
120\end{array}$ \\
\hline Homestake Mining & $\begin{array}{l}.003 \\
(.008)\end{array}$ & $\begin{array}{c}.137 \\
(.163)\end{array}$ & .770 & $\begin{array}{c}7 / 60-6 / 70 \\
120\end{array}$ \\
\hline Teledyne & $\begin{array}{l}-.015 \\
(.016)\end{array}$ & $\begin{array}{l}1.789 \\
(.286)\end{array}$ & .675 & $\begin{array}{c}6 / 66-6 / 70 \\
49\end{array}$ \\
\hline 17 Security Portfolio & $\begin{array}{l}-.001 \\
(.018)\end{array}$ & $\begin{array}{l}.672 \\
(.037)\end{array}$ & .860 & $\begin{array}{c}7 / 60-6 / 70 \\
120\end{array}$ \\
\hline
\end{tabular}




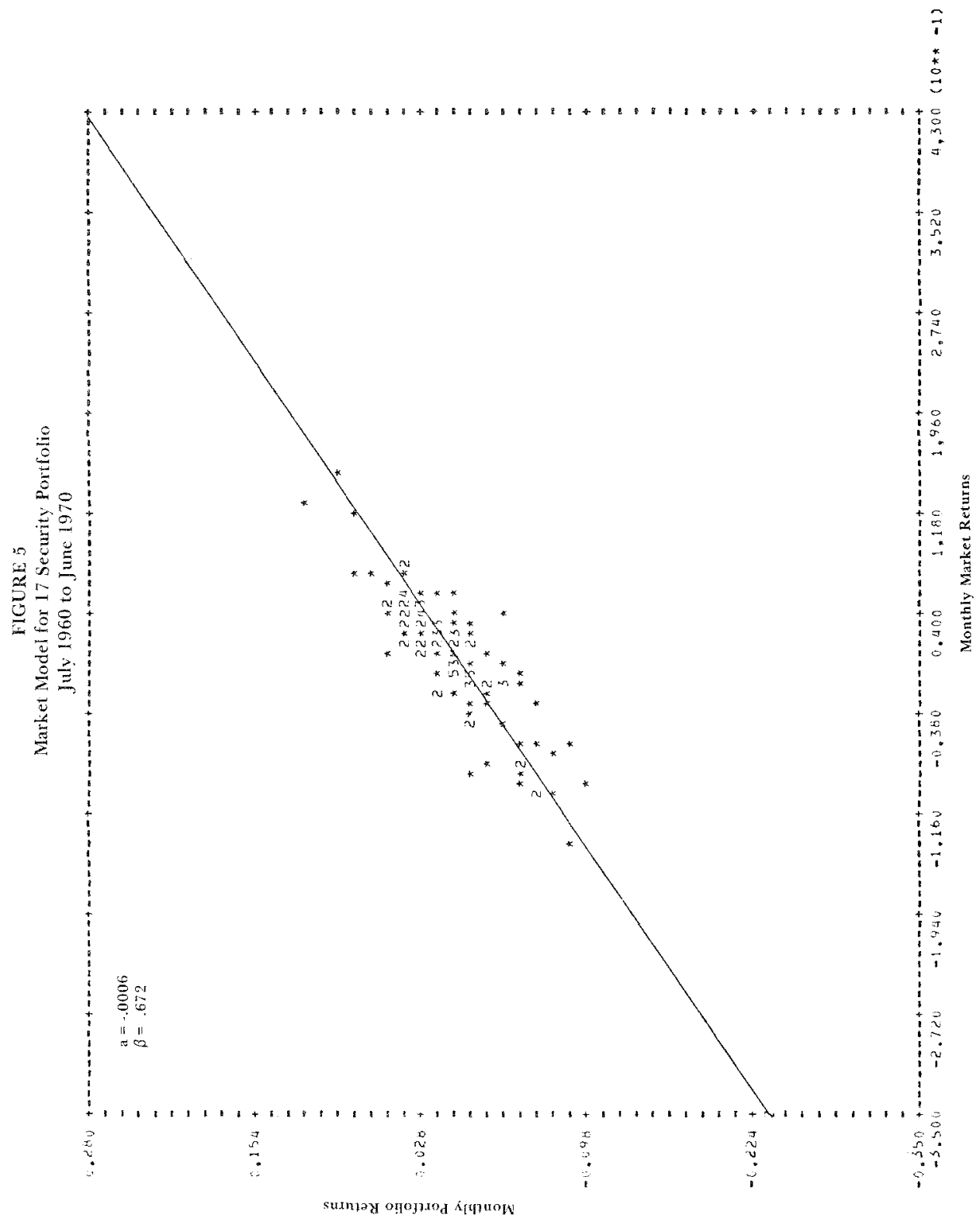


the individual securities is the very noticeable reduction of the scater around the regression of characteristic line. This is a direct rellection of the effects of diversification-the errors are on the average much smaller than for individual securities while the intercept and beta are just the average of the coefficients for the individual securities. This diversification effect is also relected in the correlation coefficient of .86 which is much higher than the average of 53 that Blume [1971] finds for individual securities over epproximately this period.

\section{Empirical Texts of the Market Model}

There has been considerable testing of the Market Model ${ }^{3}$ and the major conclusion of these tests is that the model is in general well specified. Empirical estimates of the intercept and beta coefficients do, of course, contain errors, but the evidence indicates that the beta coefficients are relatively stationary over time (especially for portfolios). This is an important result since these coefficients play an important role as the measure of systematic risk in the Capital Asset Pricing Model (as we shall see below). Blume $11970 \mid$ demonstrates that the market model can be very useful in assessing the outcomes of security returns; especially forecasts of portfolio returns conditional on forecasts of future market conditions.

If the market is rising it would clearly be desirable to hold those securities with high betas and vice versa in pcriods in which the market is falling. In addition it would be desirable to find and use as investment vehicles those securities whose betas were high in bull markets and low in bear markets. However, as the graphs indicate, there is no difference in the slope of the scatter between periods of positive and negative market returns. Systematic testing of this proposition indicates that there are apparently no securities which possess this desirable characteristic, i.e., the betas of securties appear to be unchanged in up and down markets.

In addition Blume [1971, 1974] has examined the question of the stationarity of the historially estimated beta coefficients over time in some detail. Table 2 gives the correlation coefficients between the estimated beta coefficienis for portfolios of size $\mathbb{N}=1,2,4,7,10,20$, 35 , and 50 securities for pairs of seven year time intervals in the period July 1926 through June 1968. He used data on all securities for which there was complete monthly data on the CRSP Price Relative File from 1926 to 1968 . The number of securities ranged from 415 to 890 in his 


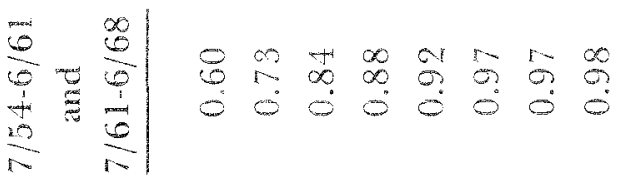

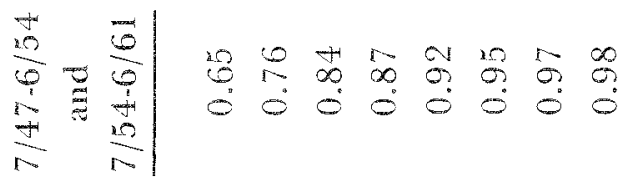

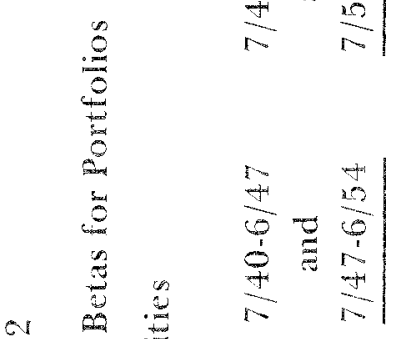

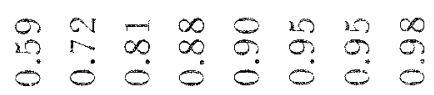

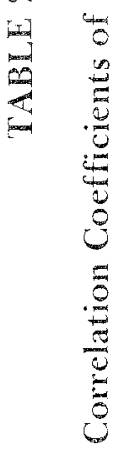

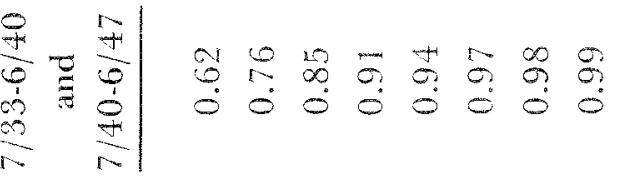

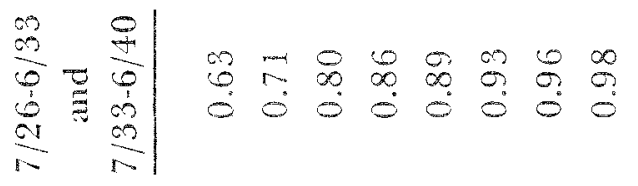

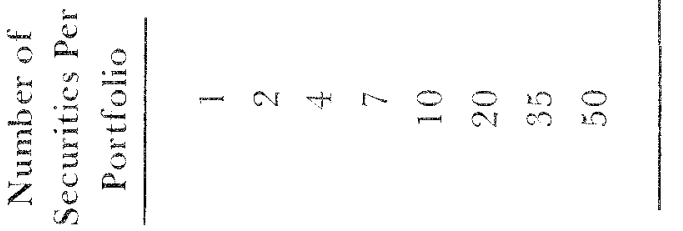

$\bar{E}$
$\bar{E}$
$\frac{0}{3}$

$\underset{8}{3}$ 
six subperiods. He constructed the portfolios by estimating the betas of individual securities, ranking them from high to low and then forming portfolios containing the first $\mathrm{N}$ securities, the second $\mathrm{N}$ securities, etc. The portfolio returns were then estimated in the first period and in the second period noted in the column headings of Table 2. The portfolio returns in these periods were then regressed on a market index to obtain a portfolio beta for the first period (for example 7/26-6/33) and similarly for the same portfolios in the second period (i.e., 7/33-6/40). These beta coefficients for each portfolio of size $\mathrm{N}$ were then correlated with each other to obtain a measure of the accuracy of the historical beta as an estimator of the future beta. As can be seen from Table 2, these correlations are quite high, ranging from .59 to .99 -especially for portfolios containing 10 or more securities. Note that the squared correlation coefficient measures the percentage of variation in the future estimates of betas explained by the historical betas. Thus roughly 36 percent of the variation in future individual security betas is explained by the historical betas and 96 percent of the variation in betas for portfolios of 50 securities is explained by the historical betas. Thus, simple extrapolations of past betas appear to provide very good forecasts of future betas for large portfolios but somewhat poorer forecasts for individual securities and small portfolios.

Blume [1971, 1974] also provides evidence that the betas tend to regress towards the overall mean beta of 1.0. That is, securities with estimated betas greater than unity in one period have betas greater than unity in a future period but the future beta tends to be closer to unity and vice versa for low beta stocks. One can adjust for this regression tendency in making forecasts of $\beta$ and Figure 6 provides a graphical illustration of the accuracy of the historical portfolio beta estimated from three years of past monthly data (for portfolios of 30 stocks) as a predictor of the beta over the subsequent year. Levitz [1974] studied the predictability of future portfolio betas for portfolios of 30 and 40 securities over the priod 2/63-1/71 for 800 stocks and Figure 6 characterizes the results he obtained from using past betas adjusted for the regression tendency for three different subperiods and two portfolio sizes. Levitz used an approximation to Blume's [1971] estimates of the regression tendency to obtain an adjusted beta. The equation used was: 4

$$
\hat{\beta}_{\mathbf{t}}=.30+.75 \beta_{\mathrm{t}-1}
$$




\section{FIGURE 6}

The Accuracy of the Adjusted Betas of 2430 -Stock Portfollos in Predicting Thelr Befas During the Subsequent Year

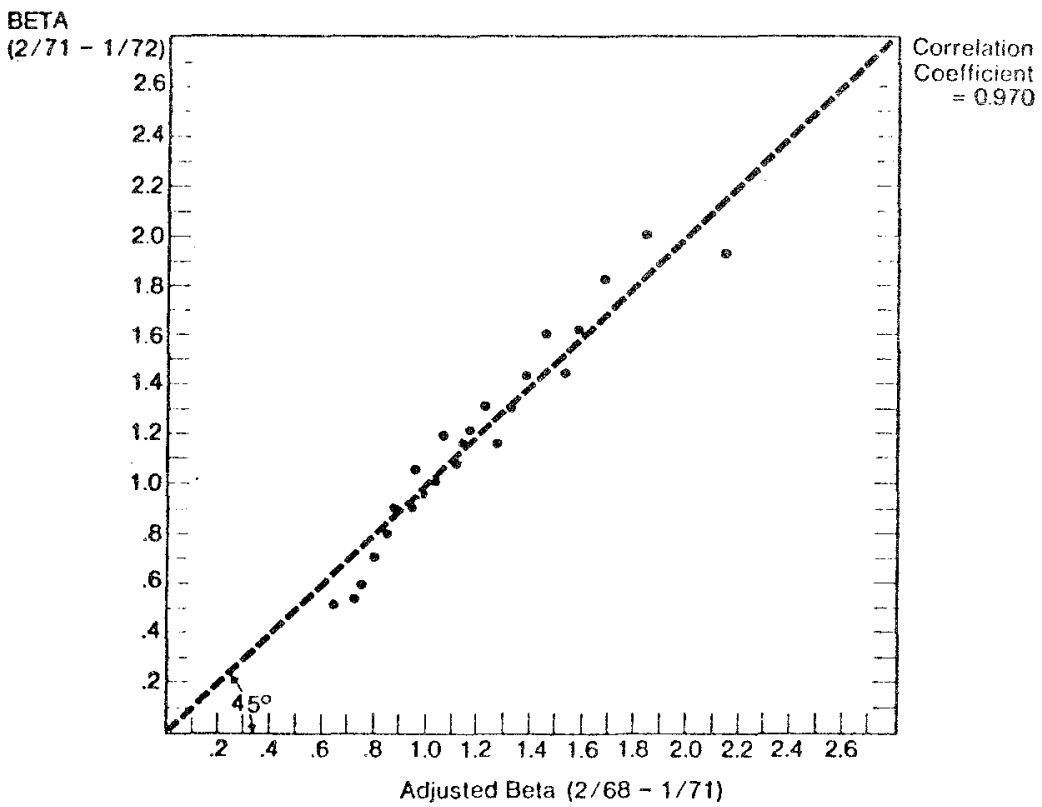

Source: Levitz [1974] 
where $\beta_{t-1}$ is the beta estimated from the previous three years of monthy portfolio retums and $\hat{\beta}_{i}$ is the adjusted forecast of the portfolio beta over the next year (obtained from weekly data). Figure 6 presents a plot of the actual beta for the period 2/71-1/72 (estimated from weekly data), $\beta_{71.72}$ vs. $\widehat{\beta}_{68-71}$, the adjusted beta estimated from monthly data in the period $2 / 68-1 / 71$. Perfect forecasis would, of course, lie on the $45^{\circ}$ line and as one can see, the forecasts were very good with a correlation of .97 with the future beta.

In addition to this evidence regarding the predictability of individual security betas and the betas of portfolios of constant composition, Jensen [1969] and Pogue and Conway [1972] have examined the predictability of the betas of managed portfolios such as mutual funds. Even if the betas of individual securities are stationary though time there is no a priori reason for the betas of managed funds to remain constant. The manager can change it easily by making systematic changes in the portfolio composition. However, the evidence indicates the systematic risk levels of portfolios are fairly constant over time indicating that managers tend to follow relatively constant risk policies. Figure 7 is a plot of the beta coefficients estimated from annual data on 56 mutual funds in the 10year period 1955-1964 versus the betas for the same funds estimated in the period 1945-1954 presented by Jensen [1969]. The correlation between the two samples was 0.74. Pogue and Conway [1972] performed similar tests on a sample of 90 mutual funds in the periods $6 / 70-10 / 71$ vs. 1/69-5/70. They estimated the betas over the two intervals on daily, weekly and monthly fund returns. The correlations between the betas were respectively $.915, .895$ and .703 for the daily, weekly and monthly betas. This is consistent with the Jensen results and also provides evidence of the benefits obtained by estimating the betas over shorter as opposed to longer differing intervals. As the frequency of observation of the retums increases (i.e., weekly as opposed to monthly) for a given total time interval, the number of return observations used in estimating betas increases. This decreases the measurement error in the estimates and thus increases the precision of the estimates. ${ }^{5}$ Since some of the prediction error is due to this pure measurement exror, this increased precision will also increase the correlation of the estimates between present and future betas.

The major assumption of the Market Model which is not confirmed by the tests is the assumed independence of the error terms, $\mathrm{e}_{\mathrm{jt}}$, among all securities. King [1966] demonstrates that these errors are 


\section{MOCLE:}

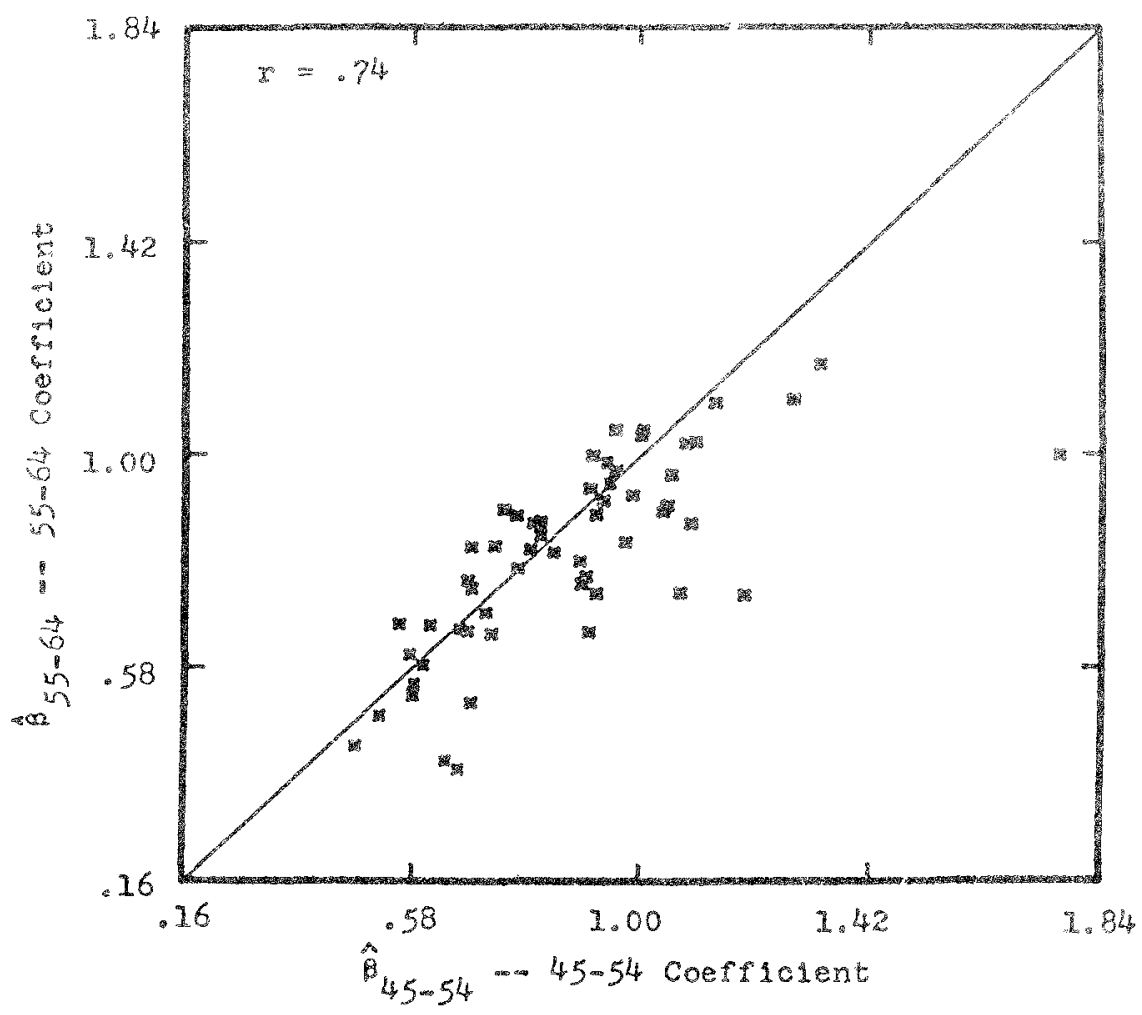

Figure 7 -- Scatier diagram of the estimated risk coefficients obtained for fifty-six mutual funds in two tertyear periods $1945-54$ and $1955-64$.

Source: Jensen [1969] 
correlated across securities for a given time period and that these correlations can be related to industry effects. Friend and Blume [1970], Black, Jensen and Scholes [1972], and Fama and MacBeth [1973] also present indirect evidence of the non-independence of these errors. 


\section{NOTES}

1. The data were obtained from the Center for Research in Security Price (CRSP) monthly price relative file at the University of Rochester.

2. To see this note that the returns on the market index $R_{M}$, for month $\mathrm{t}$ are defined to be the average return for all securities (represented by $\mathrm{N}$ ) for that month. Using this definition and substituting from (1) we have

$$
\begin{gathered}
R_{M t}=\frac{1}{N} \stackrel{j}{\Sigma}_{=}^{N} R_{j t}={ }_{j} \stackrel{N}{=} \frac{1}{N}\left(a_{j}+\beta_{j} R_{M t}+e_{j t}\right) \\
=\bar{a}+\bar{\beta} R_{M t}+\bar{e}_{t}
\end{gathered}
$$

where $\overline{\mathrm{a}}, \bar{\beta}$, and $\overline{\mathrm{e}}_{\mathrm{t}}$ are respectively the average intercept and slope coefficients and average error term. Since $R_{M t}$ must equal itself we see from this equation that $\bar{a}$ must be $0, \bar{\beta}$ must be 1.0 and $\bar{e}_{t}$ must be 0. (See Fama [1968] for a more detailed discussion of this point.)

3. See, for example, King [1966], Fama, Fisher, Jensen and Roll [1969], and Blume [1970, 1971].

4. While the adjustment equation used by Levitz seems to work fairly well it has the undesirable property that it will cause the adjusted $\beta$ for estimates slightly less than 1.0 to be greater than 1.0 , and will increase the $\beta$ (and therefore move it aw ay from the mean) for estimates in the range 1.0 to 1.2 . This is inconsistent with the observed evidence that the betas tend to regress towards the mean over time. In order to be consistent with this observation the coefficients in the adjustment equation should sum to 1.0.

5. Note, however, that the degree of precision of the estimated mean return for a portfolio or security depends on the total length of the time interval of observation and not on the frequency of the observations within the in terval. 


\section{REFERENCES}

1. Black, Fischer; Jensen, Michael C.; Scholes, Myron. "The Capital Asset Pricing Model: Some Empirical Tests," in Studies in the Theory of Capital Markets, Michael C. Jensen (editor) (Praeger Publishers, 1972).

2. Blume, Marshall. "Portfolio Theory: A Step Towards Its Practical Application," Journal of Business (April, 1970), pp. 152-173.

3. Blume, Marshall. "On the Assessment of Risk," Journal of Finance (March, 1971), pp. 1-10.

4. Blume, Marshall. "The Behavior of Risk and Retum: An Econometric Study," (Rodney White Working Paper, 1974, unpublished).

5. Fama, Eugene F. "Risk, Return and Equilibrium: Some Clarifying Comments," Journal of Finance, Vol. 23, No. 1 (March, 1968), pp. 29-40.

6. Friend, Irwin; Blume, Marshall. "Measurement of Portfolio Performance Under Uncertainty," American Economic Review (September, 1970), pp. 561-575.

7. Jensen, Michael C. "Risk, the Pricing of Capital Assets, and the Evaluation of Investment Portfolios," Joumal of Business, Vol. 42, No.2 (April, 1969), pp. 167-247.

8. Jensen, Michael C. "Performance of Mutual Funds in the Period 1945-1964," Journal of Finance (May, 1968), pp. 389-416.

9. King, Benjamin F. "Market and Industry Factors in Stock Price Behavior," Joumal of Business, XXXIX, Part II (January, 1966), pp. 139-90.

10. Levitz, Gerald D. "Market Risk and the Management of Institutional Equity Portfolios," Financial Analysts Joumal (January-February, 1974), pp. 53 ff. 
11. Pogue, Gerald and Conway, Walter. "On the Stability of Mutual Fund Beta Values," unpublished working paper, Massachusetts Institute of Technology, Sloan School of Management, June, 1972.

12. Sharpe, William F. "A Simplified Model for Portfolio Analysis," Management Science (January, 1963), pp. $277-93$.

13. Sharpe, William F. "Bonds Versus Stocks: Some Lessons from Capital Market Theory," Financial Analysts Joumal (November-December, 1973), pp. 74-80. 


\title{
CAPITAL MARKET THEORY AND IMPLICATIONS OF THE EVIDENCE-CRITIQUE
}

\author{
Frank E. Block, C.F.A.
}

Professor Jensen has reviewed the market model and some of the evidence supporting it in a most concise and lucid manner. We have no quarrel with what he has said, but we do have some reservations about the model itself.

Perhaps a good deal of the financial analyst's intuitive rejection of the academic model is a feeling that (1) the model is not expressed in terms with which the practitioner can easily identify and (2) the suspicion that academia is saying that the return from stocks is a result of the return of the market itself (Professor Jensen is careful to avoid this error in his paper). The truth, of course, is that market returns are simply the weighted average of the returns of stocks, and not the other way around. The association of a stock return with market returns exists only to the extent that it is influenced by the same external factors that dominate stock returns generally-such factors as interest rates, inflation, confidence, demographics, tax rates, and the like.

Over a long period of history the stock market itself has provided a return of perhaps eight or nine percent. The market model for an individual stock says that, on average, we will receive a return of beta times whatever return the market offers for that period of time, plus (or minus) alpha. If the market does nothing (that is, provides a zero return) then we are still entitled to a return of alpha.

The problem is that a stock with a beta of 1.5 , seems to be promising a long-term systematic return of 1.5 times, say, nine percent, or 13.5 percent. Yet when we review the list of companies having 1.5 betas, we find a mixture of (1) volatile and cyclical stocks which have had no history of such large returns and (2) growth stocks. The cyclicals generally turn out to have large negative alphas, particularly if the betas were calculated properly-i.e., peak-to-peak or trough-to-trough over one or more market cycles. Even the growth 
stocks are likely to have negative alphas, although the pattern is less clear. A good example is shown in Cohen, Zinbarg and Zeikel's Investment Analysis and Portfolio Management, on page 768. Ninety NYSE and ASE stocks having the highest 52-week betas are shown. Seventy-eight have negative alphas!

The opposite phenomenon appears on low beta stocks. Positive alphas show up far too frequently. The problem is that market model beta magnifies the underlying market return as well as the variations in market returns. Conceptually, the risk adjustment should be from a normal return, rather than from a zero market return.

The market model can be expressed diagrammatically as follows:

Market Model

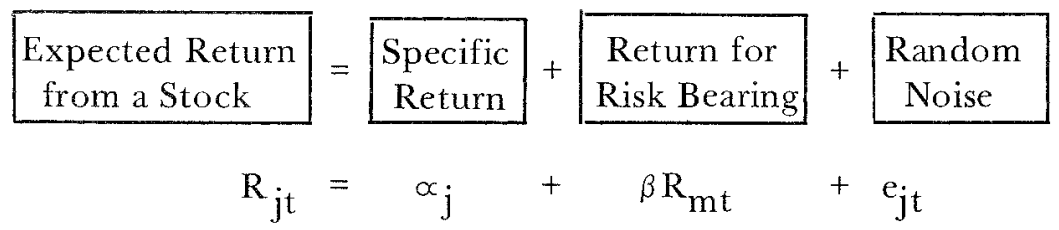

The specific return, of course, is alpha. Each alpha is unique to a given stock, and the average of all alphas has to be zero. The second element on the right-hand side of the equation is the systematic return, or simply beta multiplied by the return from the stock market for the period. The final item is random noise with an average expected value of zero.

We would like to suggest an amendment which would parallel the work that analysts do already and therefore makes the market model intuitively more pleasing to practitioners as a whole. This model would read as follows:

\section{Amended Market Model}

\begin{tabular}{|c|c|c|c|}
\hline $\begin{array}{c}\text { Expected Return } \\
\text { from a Stock }\end{array}$ & $=\begin{array}{l}\text { Different Kind of } \\
\text { Specific Return }\end{array}$ & $+\begin{array}{c}\text { Adjustment for } \\
\text { Market Risk }\end{array}$ & $+\left[\begin{array}{c}\text { Random } \\
\text { Noise }\end{array}\right.$ \\
\hline $\mathrm{R}_{\mathrm{jt}}$ & {$\left[\propto_{j}+\beta\left(R_{n}\right)\right]$} & $+\beta\left(\mathrm{R}_{\mathrm{mt}}-\mathrm{R}_{\mathrm{n}}\right)$ & $e_{j t}$ \\
\hline
\end{tabular}

Consider how an analyst typically predicts retums for common stocks. He calculates the likely return as (approximately) the sum of the grow th rate,the yield, and the rate of change in the multiple. This total rate of return is calculated over some useful time horizon on every 
stock being considered for use by his institution. This return is already in his files, but would provide a much larger "alpha" component (or, specific return) than the one used in the academic market model. In effect, it would be the total return expected from the stock.

How much would this new alpha exceed the old one? To answer the question, a number we need is the expected normal longer term return from the market itself. One would be inclined to select a number that considered historial market returns and any reasonable arguments for expecting the future to be different from the past. For purposes of discussion let us assume that, say, nine percent is the expected future rate of return for the stock market generally. With this as a bench mark, the new alpha, or specific return, would exceed the old one by an amount equal to the beta for the particular stock multiplied by nine percent.

Having added beta times nine percent to the first element on the right-hand side of the equation, it must be substracted somewhere else. It makes no sense to subtract it from the random noise, which we don't really need much anyway. Therefore let us subtract it from the second component on the right-hand side of the equation. Thus, the second component would now read $\beta\left(R_{m i}-R_{n}\right)$, or $\beta\left(R_{m t}\right.$ - nine percent $)$, where $R_{m t}$ is the expected rate of return from the market over the same period for which the (new) alpha was projected, and $R_{n}$, the nine percent of course, is the long-term expected return from the market.

What does the second component of the equation, as amended, now provide? - simply that portion of the return that can be attributed to expected departures from the normal level of market return. Thus, the second component is no longer a mixture of return and risk, but rather a simple risk or variability measure. The analyst may or may not choose to estimate this element. Over very long time horizons, it will be zero. If an opinion is held on the market return for the appropriate time horizon, the Amended Market Model provides an absolute return forecast for that time period. If the market return is arbitrarily assumed to be normal, the second element becomes zero and the equation becomes an estimate of return relative to the market. Over the shorter time periods, if no strong opinion is held about market returns, the analyst could simply substitute, say, plus or minus one standard deviation. The opportunities to manipulate the Amended Market Model are expanded by its similarity to the sort of relative and absolute forecasts which analysts are already making. The conventional model is clumsy in this respect. 
Lest we upset some of our friends in academia, it should be pointed out that all we have really done to the graph of the characteristic line is to move the vertical axis (zero) to the right by nine percentage points, or so. (At that point, the vertical axis should fall approximately on the center of moment, thereby removing some of the statistical problems concerning the reliability of estimated alphas.) All of the points representing observations would be plotted in their same relative position to the line, and the slope of the line $(\beta)$ would remain unchanged.

We would submit that the amended market model is more useful in terms of the sort of return and risk estimates currently made by practitioners than is the academic market model, and that it therefore deserves some study for possible use in developing theoretical constructs, as well as possible practical applications in such areas as performance measurement. 


\section{LONG TERM INVESTING}

\section{Jack L. Treynor}

The investor who would attempt to improve his portfolio performance through unconventional, innovative research is currently being challenged on three fronts: (1) The efficient marketers say he will be unable to find any ideas that haven't been properly discounted by the market; (2) Lord Keynes says that even if he finds these ideas his portfolio will be viewed as "eccentric" and "rash" by conventionally minded clients (and by his professional peers); and (3) finally, the investment Philistine says that even if he stands by his ideas he won't be rewarded because actual price movements are governed by conventional thinking, which is immune to these ideas.

1. Successful response to the first challenge lies in distinguishing between two kinds of investment ideas: (a) those whose implications are straightforward and obvious, take relatively little education or special expertise to evaluate, and consequently travel quickly (e.g., "hot stocks"); and (b) those that require reflection, judgment, special expertise, etc., for their evaluation, and consequently travel slowly. (In practice, of course, actual investment ideas lie along a continuous spectrum between these two polar extremes, but we can avoid some circumlocution by focusing on the extremes.) Pursuit of the second kind of idea-rather than the obvious, hence quickly discounted, insight relating to "long-term" developments-is, of course, the only meaningful definition for "long-term investing."

According to Professor Eugene Fama, "disagreement among investors about the implications of given information does not in itself imply market inefficiency unless there are investors who can consistently make better evaluations of available information than are implicit in market prices." Thus when one talks about market efficiency it is important to distinguish between ideas that require thoughtful analysis and ideas that don't: if the market is inefficient, it is not going to be inefficient with respect to ideas understood with a 
minimum of education or special training, since, by definition, these ideas are unlikely to be misevaluated by the great mass of investors.

Under what circumstances will investors' errors in appraising information available to all lead to investment opportunities for some? If investors disagree on the value of a security even when they have the same information, their differences in opinion must be due to errors in analysis. If investors err independently, then a kind of law of averages operates on the resulting error in the market consensus. If enough independent opinions bear on the determination of the consensus price, the law of "large numbers" effect will be very powerful, and the error implicit in the consensus will be small compared to errors made on the average by the individual investors contributing to the consensus.

The key, however, to the averaging process underlying an accurate consensus is the assumption of independence. If all-or even a substantial fraction-of these investors make the same error, then the independence assumption is violated and the consensus can diverge significantly from true value, and the market ceases to be efficient in the sense of pricing available information correctly. I see nothing in the arguments of Fama or the other efficient markets advocations to suggest that large groups of investors may not make the same error, particularly in appraising the kind of abstract ideas that take special expertise to understand and evaluate, and that consequently travel relatively slowly.

Thus Fama's statement can best be revised to read: "Disagreement among investors due to independent errors in analysis does not necessarily lead to market inefficiency." If the independence assumption is violated in practice, every violation represents a potential opportunity for fundamental analysis.

2. The assertion that the great bulk of practicing investors find long-term investing impractical was set forth almost forty years ago by Lord Keynes:

Most of these persons are in fact largely concerned not with most superior long-term forecasts of the probable yield of an investment over its whole life, but with foreseeing changes in the conventional basis of evaluation a short time ahead of the general public. They are concerned not with what an investment is really worth to a man who buys it for keeps, but with what the market will evaluate it at under the influence of mass psychology three months or a year hence. 
Obviously, if an investor is concerned with how the "mass psychology" appraisal of an investment will change over the next three months, he is concerned with the propagation of ideas that can be apprehended with very little analysis and that consequently travel fast.

On the other hand, the investment opportunity offered by market inefficiency is most likely to arise with investment ideas that propagate slowly, or hardly at all. Keynes went on to explain why practical investors are not interested in suchideas:

It is the long-term investor, he who most promotes the public interest, who will in practice come in for the most criticism, wherever investmont funds are managed by committees or boards or banks. For it is in the cssence of his behavior that he should be eccentric, unconventional and rash in the eyes of average opinion. If he is successful, that will only confirm the general belief in his rashness; and if in the short run he is unsuccessful, which is very likely, he will not receive much mercy. Worldly widom teaches that it is better for reputation to fail conventionally than to succed unconventionally.

Thus Keynes not only described accurately the way most professional investors still behave; he also supplied their reasons for so behaving. It is noteworthy, however, that he was careful never to say that the long-term investor who sticks by his guns will not be rewarded.

But is the price of unconventional holdings as high as Keynes alleges? Modern portfolio theory says that the holding of an individual security can be assessed only in the context of the overall portfolio: So long as the overall portfolio has a reasonable level of market sensitivity and is reasonably well diversified, the beneficiary has nothing to fear from "unconventional" holdings-and still less to fear from conventional holdings bought for unconventional reasons. There is, of course, marketing advantage in holding securities enjoying wide popular esteem but, as investors as a class become more sophisticated, professional investors are less likely to be challenged on specific holdings.

3. There is finally a widely held school of thought that asserts that research directed toward improving our analytical tools is automatically impractical because it does not describe the behavior of a market consensus based on opinions of investors unfamiliar with these 
tools. This line of argument puts a premium on investment ideas that have broad appeal or are readily persuasive, while rejecting the ideas that capture abstract economic truths in terms too recondite to appeal to the mass of investors.

The investment Philistine who asserts that it is impossible to benefit from superior approaches to investment analysis if the market consensus is not based on these approaches misunderstands what appraisal of a security means: An analyst's opinion of the value of a security is an estimate of the price at which, risk-adjusted, the return on the security is competitve with the returns on other securities available in the market. A superior method for identifying undervalued securities is therefore tantamount to a method of identifying securities which at their present prices offer superior long-term returns. The mere inclusion of such securities in a portfolio will guarantee a superior investment performance.

Suppose, for example, that the investor identifies a stock for which the market persistently underestimates actual earnings. We can formalize this idea by appealing to a standard stock valuation model such as the Gordon-Shapiro model. For simplicity, the Gordon-Shapiro model assumes that: (1) the future dividend payout ratio will be constant over time; and (2) the percentage rate $g$ at which earnings (hence, given (1), dividends) grow will be constant over time. The value of the stock equals the present worth of the growing stream of dividends, discounted at rate $\rho$ (i.e., the "cost of capital").

Let the ratio $\lambda$ of the consensus forecast of earnings at any point in time to true earnings (which, assuming the consensus correctly anticipates the constant payout rate, will also be the ratio of the consensus forecast of dividends to true dividends) also be constant over time. Then true earnings, true dividends, the consensus forecast of earnings, and the consensus forecast of dividends will all grow at the same rate $g$. If $\lambda$ equals one (i.e., if the consensus correctly anticipates future earnings), return (dividends and appreciation combined) to the shareholder $p^{\prime}$ will equal $p$, the cost of capital. If $\lambda$ is less than one (i.e., if the consensus consistently underestimates future earings), the return to the shareholder $p^{\prime}$ will exceed the cost of capital. The difference, $p^{\prime}-$ $\rho$, is the shareholder's reward for being right when the consensus is wrong. If the consensus continues to be wrong indefinitely his reward will continue indefinitely.

The table below provides a rough basis for estimating how big the return differential $p^{\prime}-\rho$ from holding undervalued stocks will be under 
the assumption that the general mass of investors never come around to forecasting earnings correctly (see Appendix A). It should be noted that these are returns per annum. The trading rate required to realize these returns is obviously very low.

TABLE

assume $\rho=10 \%$

$\begin{array}{llc}g & \lambda & p^{\prime}-\rho \\ 0 & 0.5 & 10 \% \\ 5 \% & 0.5 & 5 \% \\ 0 & 0.67 & 5 \% \\ 5 \% & 0.67 & 2.5 \%\end{array}$

$\mathrm{g}=$ rate of growth in earnings and

dividends

$\lambda=$ ratio of market-consensus

estimate of magnitude of future

earnings to true mar-magnitude

$p^{\prime}-\rho=$ abnormal rate of return that will

be realized by holding stock indef-

initely, even if market continues to

underestimate true earnings.

\section{Summary}

To the threefold challenge, we have offered a threefold reply: (1) the efficient marketer's assertion that no improperly or adequately discounted ideas exist is both unproved and unlikely; (2) Keynes' suggestion that unconventional investing is impractical ignores the wisdom of modern portfolio theory (quite understandably, since MPT is a post-war development); and (3) the investment Philistine who says good ideas that can't persuade the great mass of investors have no investment value is simply wrong.

We can sum up our case by asking the following question: If a portfolio manager consistently exhibited the kind of abnormal returns suggested in the Table, while maintaining reasonable levels of market sensitivity and diversification, how long would it be before his investment record began to outweigh, in the eyes of his clients, the unconventionality of his portfolio holdings? 


\section{APPENDIX A}

Let $\mathrm{E}(\mathrm{t})$ be earnings of the firm at time $\mathrm{t}$, be the dividend payout ratio, $\rho$ the market discount rate (the cost of capital) and $g$ the projected growth rate. If, for the sake of argument, we define "correct" pricing of the company in terms of the well known Gordon-Shapiro formula, we have for the in trinsic value $v$.

$$
\mathrm{v}=\frac{\mathrm{bE}(\mathrm{t})}{\rho-\mathrm{g}} \text {. }
$$

If the internal return on reinvested funds is $\tau$, we have

$$
E(t)=\tau(1-b) \quad \int_{0}^{t} E(\tau) d \tau=g \int_{0}^{t} E(\tau) d \tau=E_{0} e^{g t} .
$$

If priced correctly, we have for price as a function of time,

$$
v(t)=\frac{b E_{0} e^{g t}}{\rho-g} .
$$

If underpriced by factor $\lambda$, we have

$$
v(t)=\frac{\lambda b E_{0} e^{g t}}{\rho-g} .
$$

Differentiating, we obtain the rate of price appreciation

$$
\frac{\mathrm{dv}}{\mathrm{dt}}=\lambda b \mathbf{E}_{0} \frac{\mathrm{g}}{\rho-\mathrm{g}} \mathrm{e}^{\mathrm{gt}} .
$$

From previous considerations we know that the dividend is given by

$$
\mathrm{bE}_{0} \mathrm{e}^{\mathrm{gt}} \text {. }
$$

For the price change and dividend together we have

$$
\begin{aligned}
\mathrm{bE}_{0} \text { egt } \frac{\lambda g+\rho-g}{\rho-g} & \\
\text { rate of return }=\frac{\text { price }+ \text { dividend }}{\text { price }} & =\frac{\lambda g+\rho-g}{\lambda} \\
& =\frac{p-g}{\lambda}+g .
\end{aligned}
$$

The return differential realized by holding a stock underpriced by a factor $\lambda$ is therefore

$$
\rho^{1}-\rho=\frac{\rho-g}{\lambda}-(\rho-\mathrm{g})=(\rho-\mathrm{g})\left(\frac{1}{\lambda}-1\right) .
$$

But since $\frac{1}{\lambda}$ is always positive, we have $\rho,-\rho>0$. 


\section{APPENDIX B}

How would the price of a mispriced security have to behave in the future to prevent its holder from realizing an extraordinary return?

Ordinary return is $\rho$. If we replace $\lambda$ in the previous model by $\lambda(t)$, we can state the condition as:

$$
\frac{\mathrm{d}}{\mathrm{dt}} \lambda(\mathrm{t}) \frac{\mathrm{bE_{0 } \mathrm { e } ^ { g t }}}{\rho-\mathrm{g}}+\mathrm{bE}_{0} \mathrm{e}^{\mathrm{gt}}=\rho \lambda(\mathrm{t}) \frac{\mathrm{b} \mathrm{E}_{0} \mathrm{e}^{\mathrm{gt}}}{\rho-g} ?
$$

The left-hand side is the return from a mispriced security in the more general case in which the value of $\lambda$ is changing over time. The right-hand side is the normal return on the actual (mispriced) market price. We ask: How must $\lambda$ change over time if the investor is to realize only a normal return on the mispriced security (i.e., $\lambda \neq 1$ )? Differentiating, we have:

$$
\lambda(t) b E_{0} \frac{g}{\rho-g} e^{g t}+\frac{d \lambda}{d t} \frac{b E_{0} e^{g t}}{\rho-g}+b E_{0} e^{g t}=\rho \lambda \frac{(t) b E_{0} e^{g t}}{\rho-g} .
$$

This can be simplified as follows:

$$
\begin{aligned}
\lambda(\mathrm{t}) \mathrm{g}+\frac{\mathrm{d} \lambda}{\mathrm{dt}}+(\rho-\mathrm{g}) & =\rho \lambda(\mathrm{t}), \\
(\mathrm{g}-\rho) \lambda(\mathrm{t})+\frac{\mathrm{d} \lambda}{\mathrm{d} t} & =\mathrm{g}-\rho .
\end{aligned}
$$

The solution is:

$$
\lambda(\mathrm{t})=\lambda_{0} \mathrm{e}^{(\rho-g) t}+1
$$

When $t=0$, we have:

$$
\lambda(0)=\lambda_{0}+1
$$

Hence, if $\lambda(0)<1$, we have $\lambda_{0}=\lambda(0)-1<0$.

Since the exponent $\mathrm{p}-\mathrm{g}>0$, market price must fall faster and faster to prevent investors from realizing an extraordinary return on an underpriced stock (see table following). 


\section{TABLE}

\begin{tabular}{|r|l|l|l|l|}
\multicolumn{1}{c|}{$\lambda(0)=0.5 \Rightarrow \lambda_{0}=-0.5$} \\
\cline { 2 - 5 } & \multicolumn{2}{|c|}{$\rho-\mathrm{g}=5 \%$} & \multicolumn{2}{c|}{$\rho-\mathrm{g}=10 \%$} \\
\cline { 2 - 5 } & $(\rho-\mathrm{g}) \mathrm{t}$ & $\lambda(\mathrm{t})$ & $(\rho-\mathrm{g}) \mathrm{t}$ & $\lambda(\mathrm{t})$ \\
\hline $\mathrm{t}=0$ & 0 & 0.5 & 0 & 0.5 \\
1 & 0.05 & 0.474 & 0.10 & 0.448 \\
2 & 0.10 & 0.448 & 0.20 & 0.390 \\
4 & 0.20 & 0.390 & 0.40 & 0.254 \\
8 & 0.40 & 0.254 & 0.80 & negative \\
16 & 0.80 & negative & & \\
\hline
\end{tabular}




\title{
THE CAPITAL ASSET PRICING MODEL FROM A PROFESSIONAL'S POINT OF VIEW
}

\author{
Jerome L. Valentine, C.F.A.
}

The papers presented earlier were more than sufficient to explain the assertions of the Capital Asset Pricing Model. This paper attempts to discuss only two points from the standpoint of the practicing analyst. First, what findings in the model are useful to current practice, and to what extent are the findings unrealistic. Second, what practical complexities in the market might limit the application of the model in realistic applications.

The model implies that the best portfolio will be some combination of the "market portfolio" and the risk-free asset (which could be approximated by T-bills). Even if there were not a perfect agreement among investors, each investor would have his own "best portfolio" of risky assets and then either increase or decrease his risk by borrowing or by buying T-bills. This argument is useful to the practitioner because it does not presuppose the belief that investors agree. It implies that we should re-think the idea that risk-adverse accounts should be in a different set of securities from accounts willing to accept a high level of risk. It may very well be the case that both types of accounts should have the same stock portfolio, but the former should have a high percentage of assets in cash equivalents in order to reduce risk. This concept has some intuitve appeal, for it places all accounts in the "best" set of stocks, and separates the risk adjustment part of the problem from the problem of equity selection, placing it in the realm of the cash-bond-equity mix decision.

Another possible benefit of the model stems from the numerous tests of the theories implying short-term randomness in security price movement. Since there is now little doubt that hourly or daily movements in prices are not predictable, the trading desk activity at institutions may need to be restructured to some extent. It is fairly common practice for traders to attempt to anticipate market behavior. 
On occasion this may cause the orders from portfolio managers to be delayed on the trading desk for quite some time. If fundamental analysis was valuable and short-term price prediction fruitless, this situation obviously should be altered.

The problem is that capital asset pricing theory, if taken literally, implies that fundamental analysis is not useful. The impact of the theory on the value of analysts is obvious. Some conceptual problems that I have in relating the theory to the actual practice of investment professionals have already been presented in a Financial Analysts Research Foundation working paper. At this time, I would like to restrict consideration to only one problem in the theory-the problem of market structure. Analysts have always held that the market's behavior is highly complex, whereas the capital market theory asserts that it is describable by a fairly simple equation relating the "market" change and the change in the price of individual securities. The balance of this paper presents some preliminary findings on a set of companies constituting over 50 percent of the market value of the S \& P 425 . Historical (or "ex post") returns were used, and the capital market theory is theory of expectations (or "ex ante") theory. Nevertheless, Jensen (in a paper published in the Bell Journal) has shown that the ex ante theory implies ex post returns which follow the "beta" equation and hence that the theory can be subjected to empirical testing. The following empirical evidence relates to the "market" concept treated as a single variable in the most fundamental portions of the thory.

The Capital Asset Pricing Model and beta theory frequently discuss the "market" as if it were a single entity easily recognized and measured by investment professionals. Actually, of course, "market behavior" is some logical construct which is known only by its footprints-its impact on individual stocks. It is possible, of course, to evaluate a number of the footprints in order to gain some insight into its path, and this is what the standard market indices attempt to do. These indices aggregate the behavior of a number of stocks in order to portray with some degree of accuracy the behavior of the "market" that lies behind each of the companies as a "common factor" influencing all companies.

A problem occurs immediately, however, since each index is an approximation of the common factor, and it is not clear which "market" index to use. Since the popular indices show quite different performances over time, it is not clear whether the beta based on one index should be preferred to the beta based on another. 
A more fundamental problem is whether the variations in this common factor that we call the "market" can be described by only one index. It is at least logically possible that two independent indices (two common factors) would be needed to adequately describe the behavior pattern of stocks. A statistical technique known as factor analysis can be used to determine the number of common factors influencing stock price behavior. If this type of analysis is applied to market swings as variables, it produces the number of "common factors" required to explain the pattern of behavior present in bull market and bear market swings.If the Capital Asset Pricing Model is correct, then one factor (the general market) could explain this entire structure. If one factor is all that is needed to predict a company's return, then the "beta" approach is a straight-forward way to perform the prediction. The possibility that this situation may in fact be the case in actual market behavior can be directly explored by using factor analysis with market swings as variables. The number of factors shown in this type of study can be interpreted as the number of independent characteristics of companies' relations to the market needed to describe their market behavior.

Table I lists the companies used in the study, and Table II identifies the beginning and ending points for the time periods chosen for the market swings. Table III shows the beta coefficients and standard errors for the companies involved. The basic results of the study can be shown for two different types of factor analysis which cxhibit comparable findings. Only the results for the first six factors are shown, but the study indicated that all six of these are significant even though beta theory implies only one.

\begin{tabular}{ccc} 
Factor Number & $\begin{array}{c}\text { Alpha Factor Analysis } \\
\text { of Explainable Variation } \\
\text { Explained by Factor }\end{array}$ & $\begin{array}{c}\text { Principle Components Analysis } \\
\text { \% of Total Variation } \\
\text { Explained by Factor }\end{array}$ \\
\cline { 2 - 3 } 1 & 27.6 & 19.6 \\
2 & 22.3 & 13.2 \\
3 & 15.4 & 11.5 \\
4 & 14.2 & 10.1 \\
5 & 12.7 & 9.7 \\
6 & 7.9 & 7.4
\end{tabular}

These results show that these is no tendency for the information. to be strongly forced into a single factor. In fact, if a statistician 


\section{TABLE I \\ Data Cases \\ Identification of Firms}

1. American Home Products

2. Atlantic-Richfield (ARCO) ${ }^{1}$

3. American Tel \& Tel

4. Avon Products

5. Burroughs

6. Caterpillar Tractor

7. Coca-Cola

8. Continental Oil

9. Dow Chemical

10. Du Pont

11. Eastman Kodak

12. Eli-Lilly

13. Exxon (Standard Oil of New Jersey)

14. Ford

15. General Electric

16. General Motors

17. Getty Oil

18. Gulf Oil

19. Halliburton

20. IBM

21. Intemational Nickel

22. International $\mathrm{Tel} \& \mathrm{Tel}$

23. International Paper

24. J. C. Penney
25. Johnson \& Johnson

26. Kresge

27. Merck

28. Minnesota Mining \& Manufacturing

29. Mobil Oil (Socony) ${ }^{2}$

30. Pfizer

31. Philip Morris

32. Phillips Petroleum

33. Polaroid

34. Procter \& Gamble

35. Royal Dutch

36. Schering-Plough (Schering) ${ }^{3}$

37. Schlumberger ${ }^{4}$

38. Sears-Roebuck

39. Shell Oil

40. Standard Oil of Califomia

41. Standard Oil of Indiana

42. Sun Oil

43. Texaco $^{5}$

44. Texas Instruments

45. Union Carbide

46. Warner-Lambert

47. Westinghouse

48. $\operatorname{Xerox}^{6}$

\section{NOTES}

1. Taken as Atlantic Refining until merger with Richfield Oil. First joint observation: $10 / 7 / 66$.

2. Taken as Socony Oil until Mobil Oil formed. First observation as Mobil: $10 / 7 / 66$.

3. Taken as Schering until merger with Plough. First joint observation: $4 / 28 / 71$.

4. Taken as Daystrom until Schlumberger formed. First observation as Schlumbergex: 6/26/62.

5. Taken as Texas Company until Texaco formed. First observation as Texaco: $8 / 3 / 59$.

6. Taken as Haloid until Haloid Xerox formed; taken as Haloid Xerox until Xerox formed. First observation of Haloid Xerox: $8 / 3 / 59$; first observation of Xerox: $12 / 12 / 61$. 


\section{TABLE II}

\section{Time Periods}

Fifteen market swings over the period from July 15, 1957 to November 30, 1973 were studied. Each date delimiting a rise or fall was selected as the highest or lowest point in the respective swing. Data on stock prices as of a given day were acquired from microfilm records of the Wall Street Joumal. When only bid-ask spreads were quoted, the bid prices were recorded and used in subsequent calculations. Several of the stocks in the studies, in the earlier part of the period, were traded over-the-counter and only bid-ask spreads were available. Information regarding stock splits and payment of dividends was obtained from the 1973 edition of Moody's Industrial Manual. Rates of retum for each stock were calculated for each market swing taking account of price change, stock splits, stock dividends, and cash dividends. The exact dates delimiting the chosen swing periods are as follows:

1. July 15,1957

2. October 22,1957

3. August 3, 1959

4. October 25,1960

5. December 12,1961

6. June 26,1962

7. February 9,1966

8. October 7, 1966

9. October 9, 1967

10. March 5, 1968

11. November 29, 1968

12. May 26,1970

13. April 28, 1971

14. November 23,1971

15. January 8,1973

16. November 30,1973

The analytic procedure followed was a Factor Analysis of 48 cases ( 48 firms) by 15 variables (rates of return for 15 market swings). 


\section{TABLE III}

\section{COMPANY}

American Home Products

Atlantic Richfield

American Tel \& Tel

Avon Products

Burroughs

Caterpillar Tractor

Coca-Cola

Continental Oil

Dow Chemical

Du Pont

Eastman-Kodak

Eli-Lilly

Exxon (Standard Oil of N.J.)

Ford

General Electric

General Motors

Getry Oil

Gulf Oil

Halliburton

IBM

International Nickel

International Tel \& Tel

International Paper

J. C. Penney

Johnson \& Johnson

Kresge

Merck

Minnesota Mining \& Man.

Mobil Oil (Socony)

Pfizer

Philip Morris

Phillips Petroleum
BETA

COEF FICIENT

0.78

1.11

0.67

1.03

1.01

1.35

0.86

1.09

0.91

0.80

0.97

0.88

0.64

1.13

1.06

0.99

1.11

0.90

1.23

1.09

0.82

1.77

0.92

1.28

1.01

1.51

0.88

1.12

0.90

0.70

0.98

0.88
STANDARD

ERROR
5.6

12.4

6.2

8.7

9.3

8.3

6.0

14.5

5.9

7.9

7.1

8.4

7.1

8.7

6.4

5.8

11.5

7.8

10.0

7.4

9.8

8.7

8.3

5.2

8.9

8.8

6.8

5.3

10.0

8.1

11.1

11.8 
TABLE III (Continued)

COMPANY
Polaroid
Procter \& Gamble
Royal Dutch
Schering-Plough (Schering)
Schlumberger
Sears-Roebuck
Shell Oil
Standard Oil of Calif.
Standard Oil of Indiana
Sun Oil
Texaco
Texas Instruments
Union Carbide
Warner-Lambert
Westinghouse
Xerox

\section{BETA \\ COEFFICIENT}

1.78

0.83

0.78

0.76

1.27

1.03

0.99

1.04

0.83

0.65

0.87

1.43

1.03

0.93

0.86

1.05 \begin{tabular}{l} 
STANDARD \\
ERROR \\
\hline
\end{tabular}

16.2

6.7

9.1

6.7

10.9

5.3

9.2

7.3

9.2

9.1

8.4

11.6

7.5

7.6

9.7

6.6 
wishing to explain companies' returns using the behavior of the "market" factors to characterize each company's behavior, chose only two, he would lose half of his already limited explanatory power. If he used only one, he would lose three-fourths of his power. Beta theory uses a one variable equation to move from a market return to a company retum, with the company characterized by only one number and the "market" approximated by only one index of doubtful reliability. It is not hard to understand why beta-based predictions of the return of individual companies are not highly reliable.

The results were so sharply at odds with the theory that a number of cross checks were made to attempt to locate some logical flow in the study. Table IV shows alpha factor analysis results (a type of factor analysis that assumes that the market swings were randomly sampled from the set of all possible swings) on the actual company price relatives (I), the logs of the price relatives (II), and the price relatives annualized (III). This might help to show whether the results stemmed from some inadequate way of presenting the company returns. As can be seen from the table, the importance of the many factors was not reduced. The middle portion of the table shows the "communalities" of the market swings - the proportion of each swing's variation that could be explained by the factors. These communalities were about the same using each of the variable lypes.

Table $V$ presents the results of studies using three types of factor analysis. "PA1" refers to the principle components analysis, "PA2" to common factor analysis, and "Alpha" to alpha factor analysis. It is not necessary to discuss the features of the techniques here. The important point is that the bottom of the table shows that multiple factors appear regardless of technique. The factor loadings in the upper portion of the table are the correlation coefficients of each of the market swings to each of the first three factors.

Table VI shows the results of the actual alpha factor analysis in Section I. Section II shows what the results would have been if the companies had behaved in accordance with their beta coefficient and a nominal standard error. Section III shows the results (by a monte carlo simulation) if they had behaved in accordance with both their beta and their standard error. Notice that Section II has only one factor explaining 100 percent of the behavior. Section III has the companies' actual standard error and shows 65 percent of the behavior explained by the data. These values compare to 27.6 percent for the first factor 


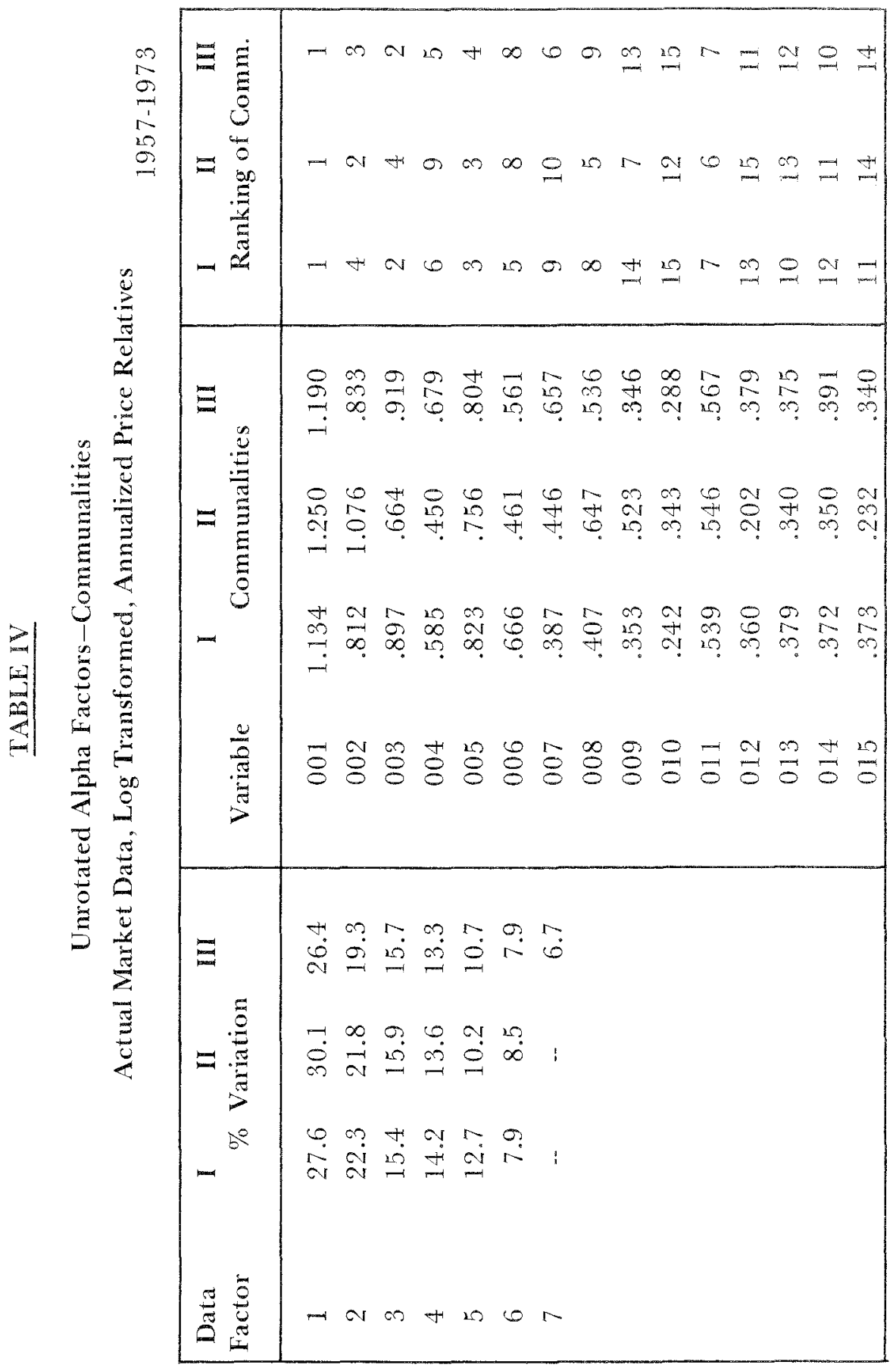




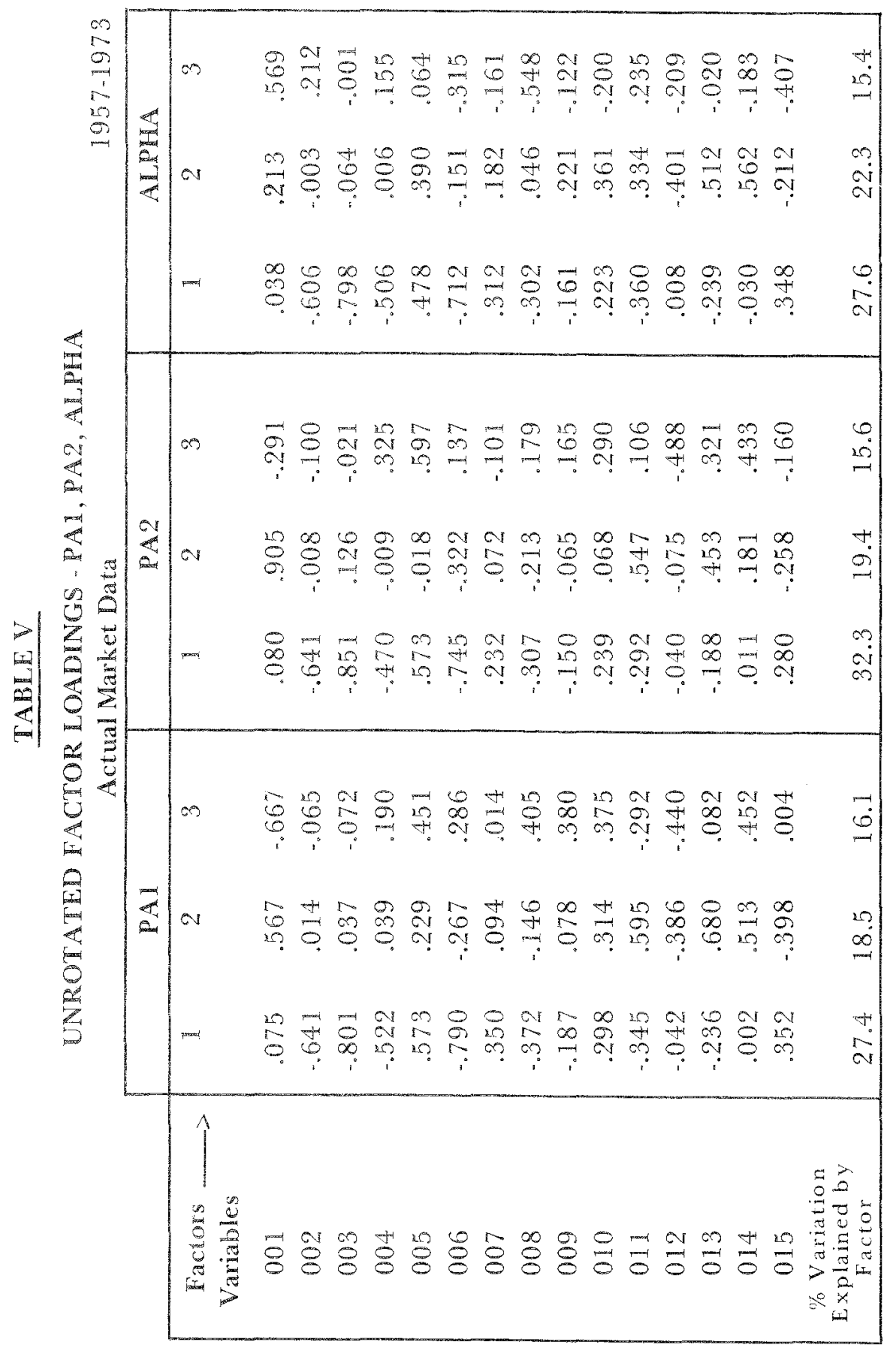




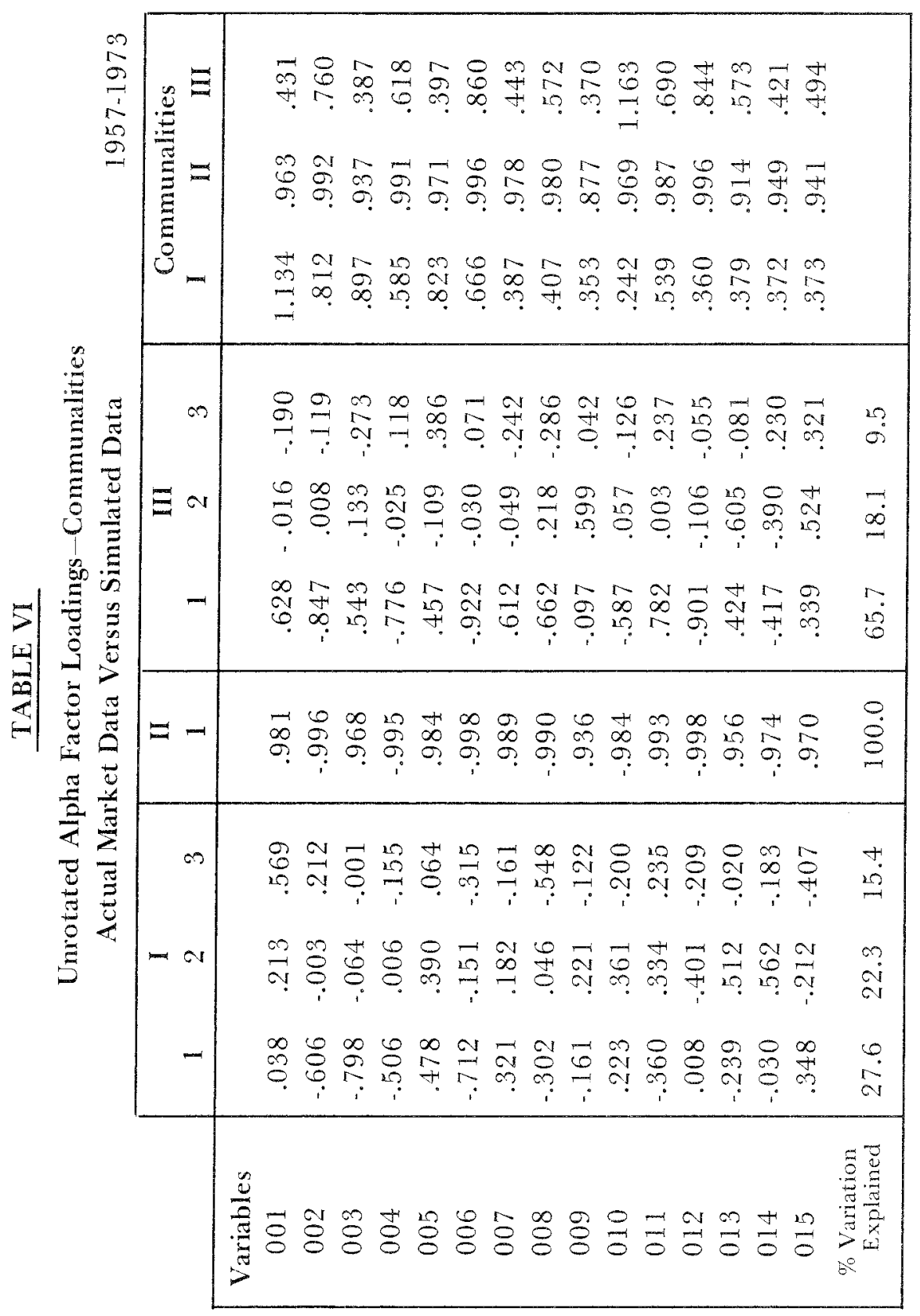


using the actual behavior of companies. In other words, the table clearly shows that the actual results are at odds with the theory.

One of the problems of factor analysis is that it tends to become too theoretical-moving too far away from the analyst's ability to understand intuitively what is happening. Graph 1,2,3 and 4 are an attempt to help avoid this difficulty to some extent. Each chart shows companies' ticker symbols in a scatter diagram of their scores on the two most important factors of one of the studies. Companies located close together would display similar price patterns. The first two charts show data for the entire time period using two different factoring techniques. The last two graphs show two different subsets of the time period in the overall study.

Graphs 5, 6, and 7 show the behavior of market swings on the factors from three different "angles" or "points of view." Swings located close to each other could be regarded as having been similar in the structure of their companies' movement.

The result of all of this probing presented in the various tables is that the structure of the market's actual behavior is substantially more complex than postulated by beta theory. Unfortunately, this is only a beginning, for how this complexity can be related to the traditional forms of fundamental analysis is a question that must be left to future research. Until additional answers are developed and incorporated in to capital asset pricing theory, however, the practicing professional would probably be well advised to continue the use of fundamental techniques. The theory to date has provided a number of practical results, but it will probably be some time before academicians or professionals will be able to capture the richness of the structure of security price movements. One number, as we have seen, is not sufficient. 


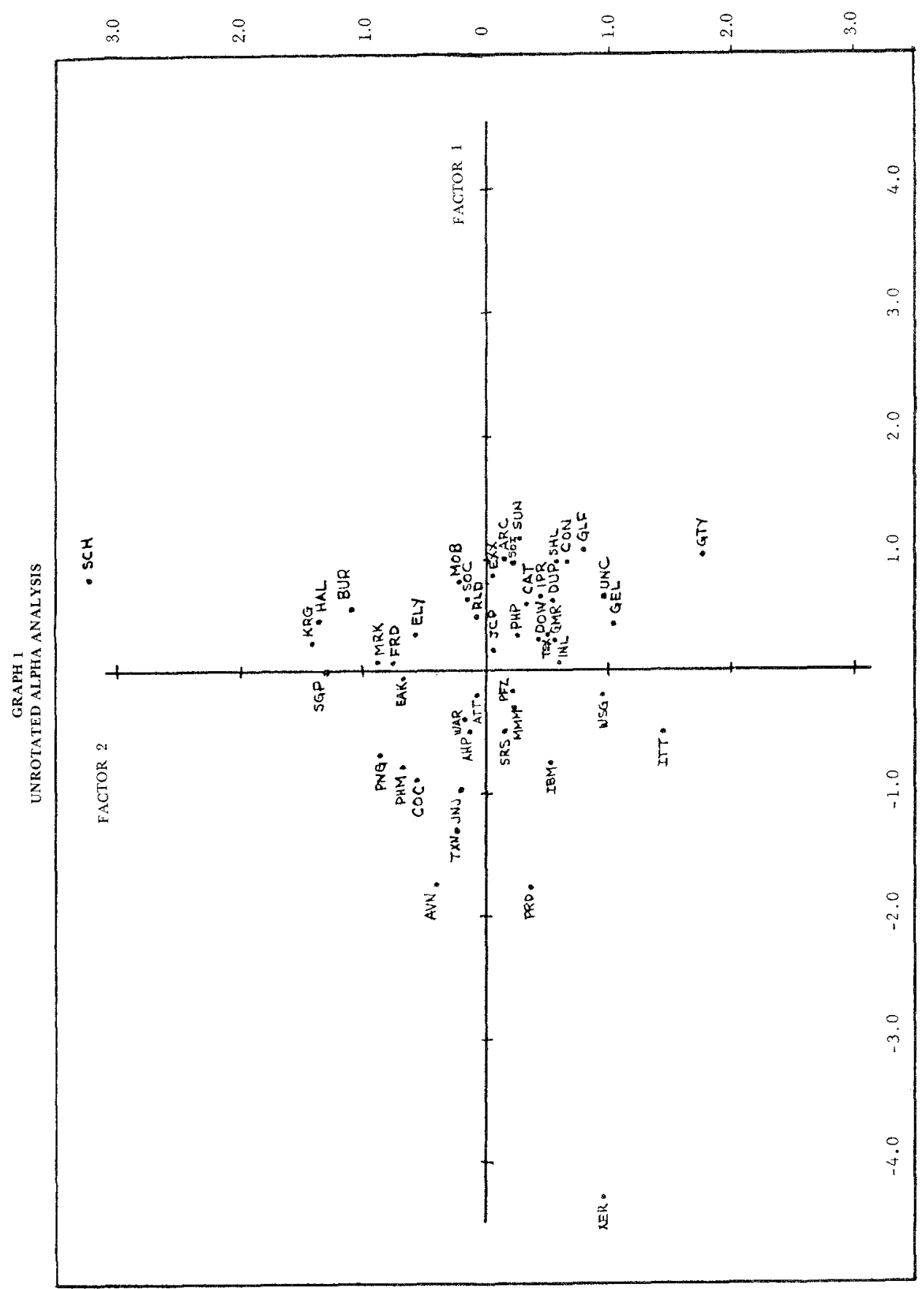




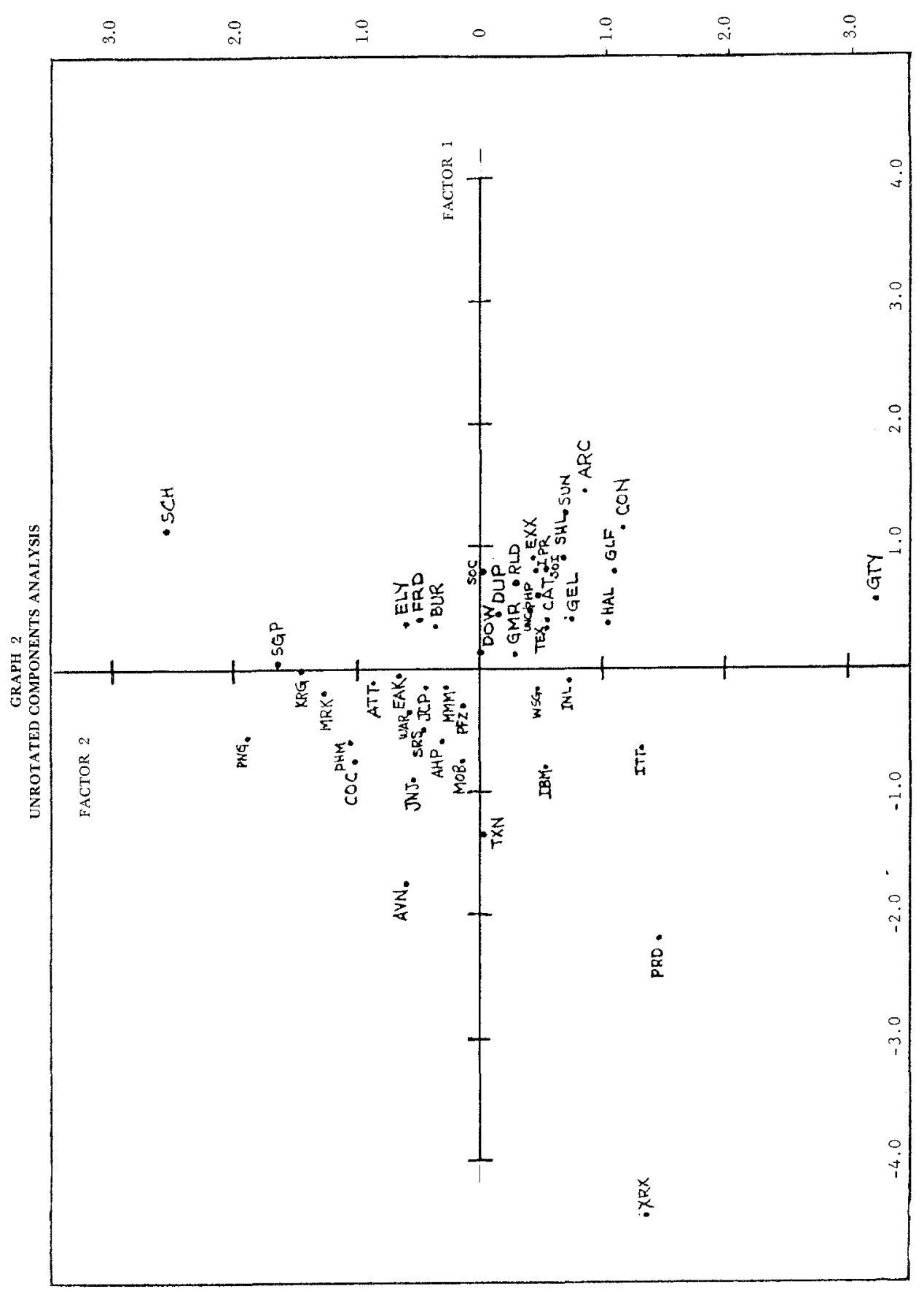




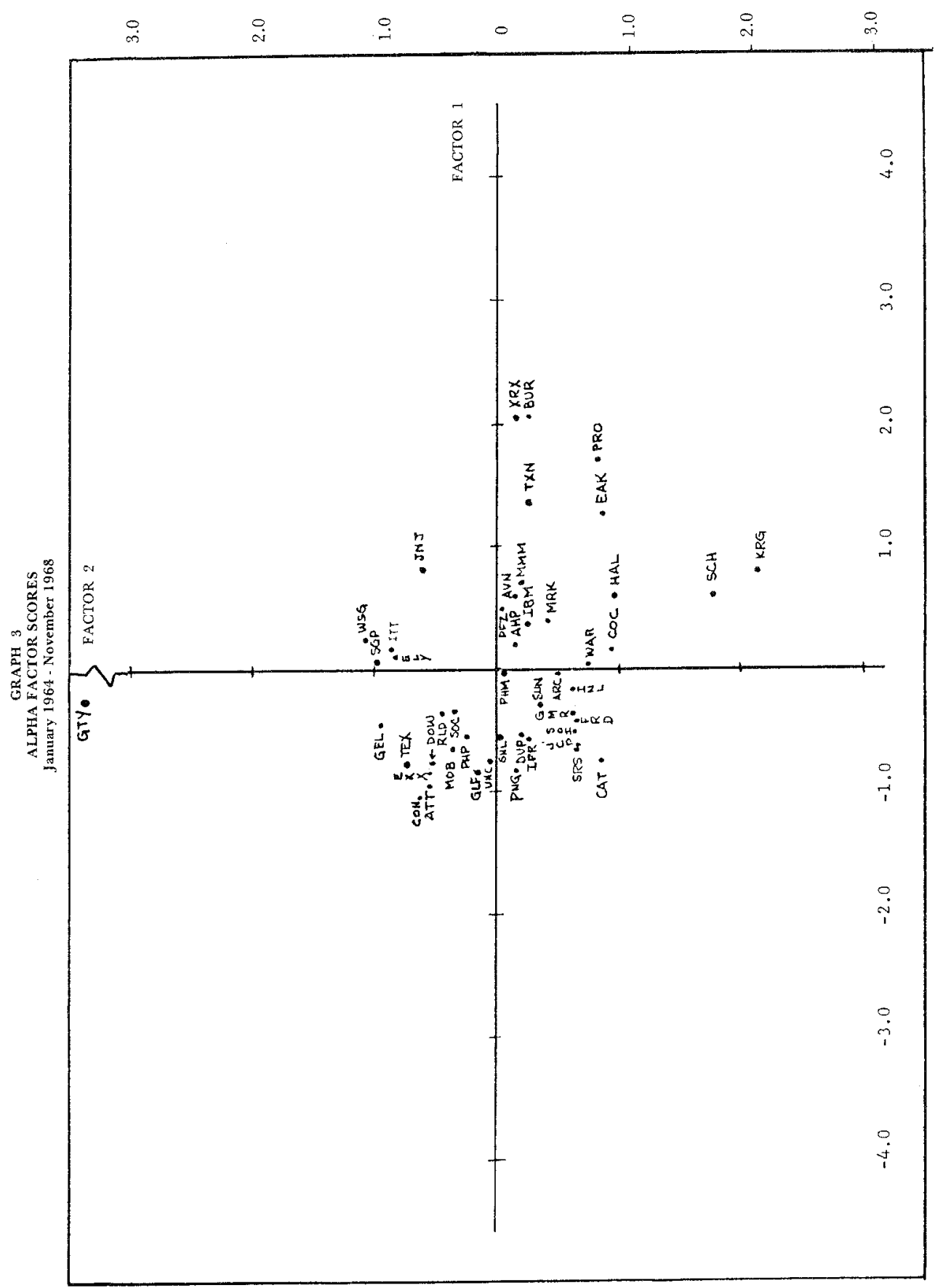




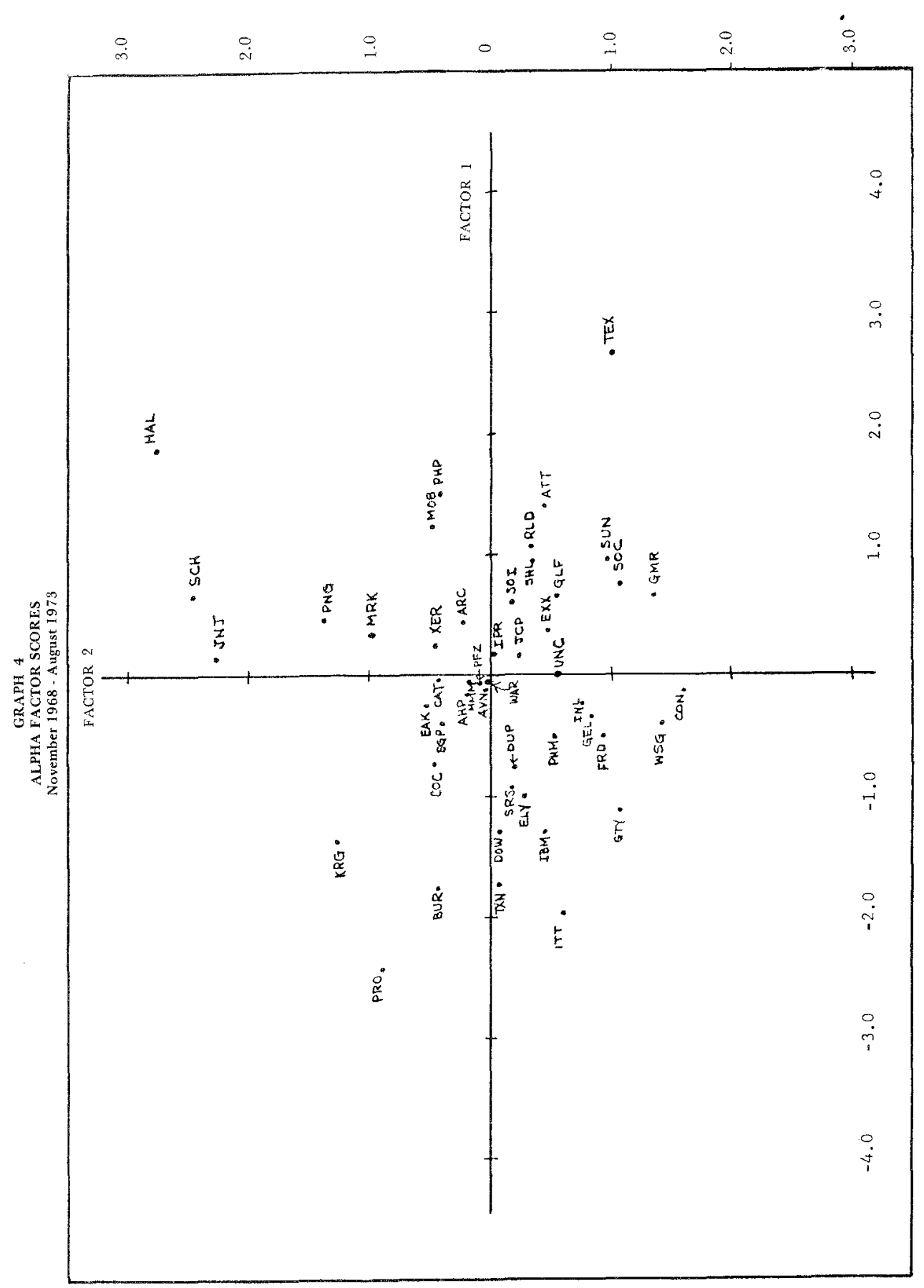




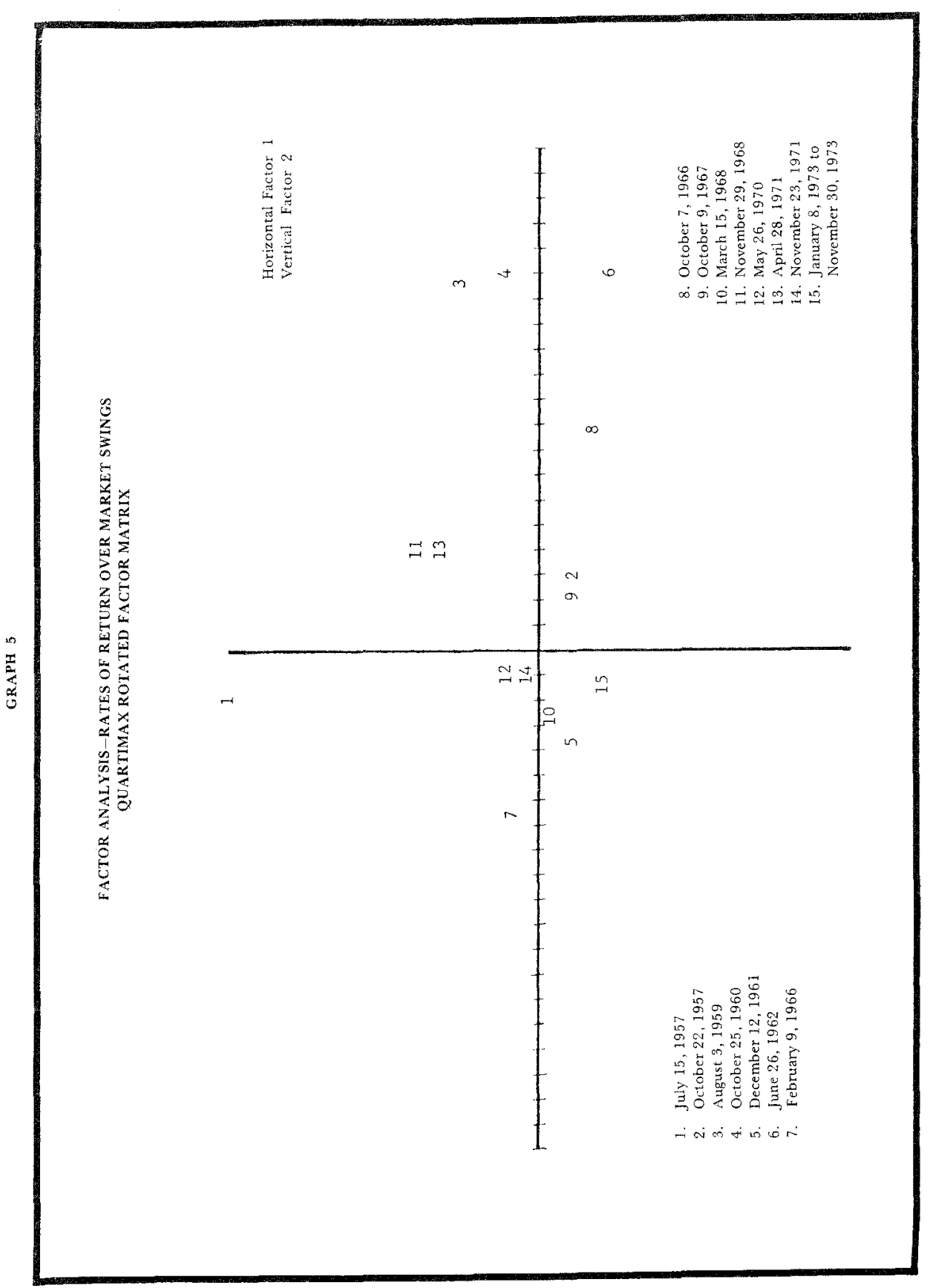




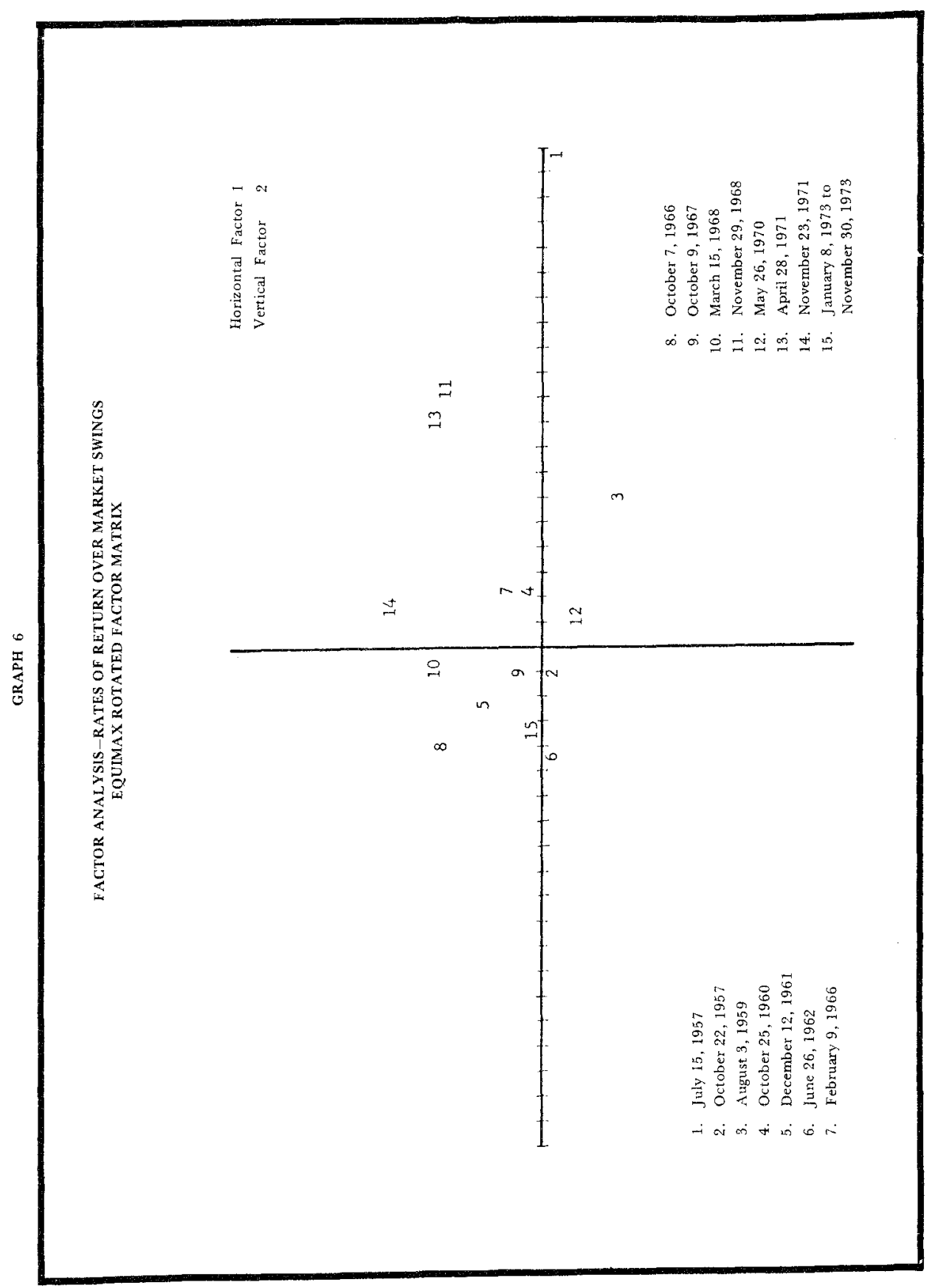




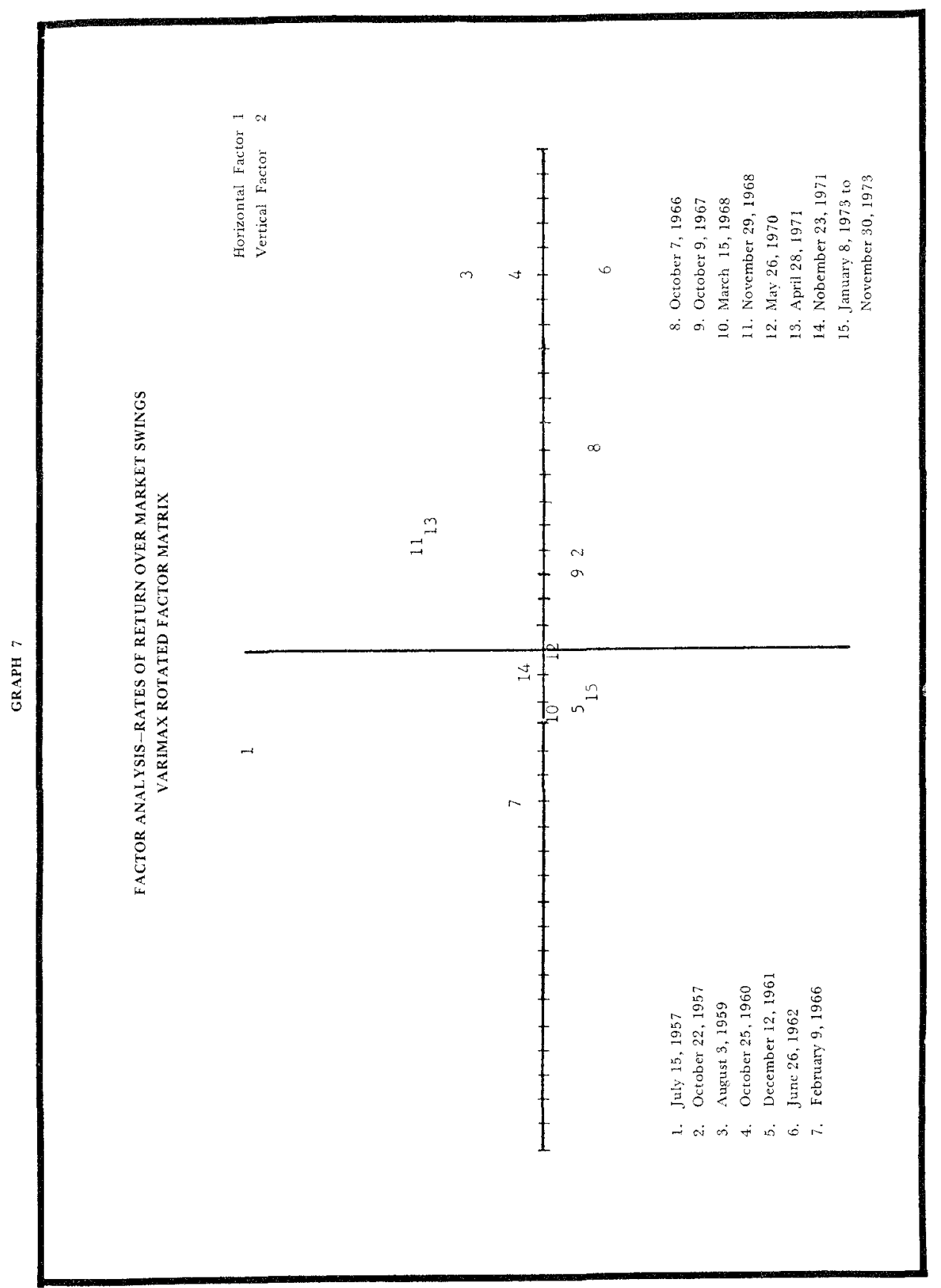




\section{DISCUSSION OF CAPITAL MARKTT THEORY}

\section{Neil Wright}

These comments will be divided into three scctions: a conccssion, a warning, and a strategy discussion. The concession is clear. Individual investors or managers who are unusually cunning can clearly make extra returns in the market over time. For example, the data on mutual funds or aggregate institutions in general does not climinate the possibility that we could have some financial analyst here who was cunning enough to be worth a million dollars a year. All of us probably can think of examples where people have been systematically cunning or systematically unwise. A few years ago, for example, the stock market systematically overvalued conglomerates because it accepted earnings growth, even when that eamings growth was generated by one company buying others with a lower price carnings ratio. I'm not certain that is quite as comforting to the financial analyst with regard to his job security, job position, and his worth to the investors who use him or to the firm that hires him as it sounds. The fact that there are few analysts out there making a fortune says very little about what the average analyst is going to be worth over time. I am reminded of stories in the Wall Street Journal that divided investors in to two groups: On one hand there were all the little investors who were "stupid" and who systematically misinvested in the stock market. On the other hand there were the "professionals" who came in and brought the stock market back in to line, although presumably not completely into line, and in the process made money. When one looked at that category of investors called "professionals" he would find that they had a return greater than that of a random market portfolio. And then, of course presumably, if one looked at the amateur investors he would find a return less than that of a random market portfolio. At least that was the conclusion in the newspaper stories. 
Jerry Valentine's paper, however, does not necessarily lead us to that type of conclusion. Studies on the mutual funds, such as the one by Jensen, suggest that professional investors as a whole are not doing better than the market on the average. This means that if you simply selected a financial analyst from the FAF Directory and didn't know anything about him, his expected value would be zero. That's a fairly serious problem for analysts to face. If analysts as a whole are just getting normal returns there might be some smart analysts getting above normal results while others are getting below normal results.

Let's take a situation where a superior analyst starts bidding up the price of certain securities that are in fact especially desirable. Holders who use standardized information automatically think they are overpriced and immediately start selling. If in fact they knew the extra information and analysis that the superior analyst knew, they would consider them underpriced. Obviously these holders did the wrong thing by selling. Success can't be as simple as merely copying the crowd. However, doing cxactly the opposite of what the conventional wisdom is in Wall Street does not always result in success either.

Let's examine the kind of strategy these considerations suggest. The efficient markets hypothesis suggests that you must have genuinely superior analysis in order to come out ahead. The best way to do this is to try to generate something that's unique and special-not merely run-of-the-mill industry studies and phone contacts with other analysts that keep your predications within the consensus range. Suppose, for example, we have an oil crisis and the stock market is gyrating wildly. Since the impact on the economy would be very hard to analyze, if I were an analyst for the duration of the crisis I would work 16 hours a day. If I were managing analysts I would work them 16 hours a day. Then when the crisis settled down I would tell everyone to go home and take a month off to compensate for the extra effort during the crisis period. Also, I would not expect the analysts to churn out lots of company reports. It seems unlikely that they are going to come up with special insights on 30 companies a year if it's hard to come up with any insights at all. I would encourage them to spend more time concentrating on a single firm until they knew what was really going on in the firm and in its industry.

Let me go on to the problem that Dr. Valentine raised relating to rank order bias. The problem is that if in retrospect you look over your own projections of what stocks were going to do, you will notice that 
on average they didn't come out quite as well as you expected. (I've noticed this problem in my own investing.)

It was suggested that this type of rank order bias could also apply in measuring betas. Suppose we wish to get as high a beta portfolio as possible with direct investments, rather than by levering with borrowing money. In that case, if we take a set of estimates of beta we will really not have as high a beta portfolio as we thought. For instance a 3.0 beta estimate might turn out to be a 2.7 beta at the end of the year. Dr. Jensen mentioned this in another context. I would like to make two observations. One is that it wouldn't occur if we were following the strategy of buying a market portfolio with beta close to one and then either by treasury bills or borrowed money sought to change our betas. This wouldn't occur because this rank order bias depends on there being a semblance of asymmetry in the securities which one is considering. If you are picking a beta around one you won't be disappointed on the average because you have as many securities with a beta above you as below you and the rank order bias would be very mild. It will only be a serious problem when you're dealing with betas or an extreme value, which as far as I can tell not many institutions do. There are very few mutual funds, for instance, that will pick stocks with betas up in the two range.

The third thing I wanted to speak of is the issue of factor analysis. I must confess that when I read it, it produced amazing results to me in the sense that six factors were found in the analysis of 48 companies. Intuitively, that means for each company, you need a market index of all 48 companies and then some market index which was a subset of that (say 25 of the 48 companies), and then some other index of a subset of companies (perhaps 15), and then another subset of 10 and another subset of 7 and another subset of 4 . That is, you would need a variety of indices so that, for instance, in describing a company you might say it's in the American Stock Market; it's a steel company; a steel company in the Eastern part of the country; a steel company in the Eastern part of the country that sells to consumers that uses some railroad system, etc. Well, if you consider 48 companies, each in different industries, etc., it becomes very difficult to understand what those six factors would have meant. Further, I'm surprised in the sense of similar studies in the past, no one has results quite like Valentine's study. King and Feenan and Hester have done the same thing and found that the first factor was more significant than the results that we have 
heard here today. That first factor being the one that would associate with beta. Thus, further work should be done before we can analyze just how many factors there are and what weight they have in individual security movements.

Finally, I would like to mention that for the present as long as we can put together portfolios that act as if beta is the one thing that matters then it really doesn't make any difference if there are six factors underneath what the stocks are doing. It may make some difference if you're trying to do some analysis on rate of return, which can be very important. In terms of portfolio management, however, we can concentrate on beta and not worry about other factors. 